\title{
Processes for Pretreating Lignocellulosic Biomass: A Review
}

\author{
J. D. McMillan
}

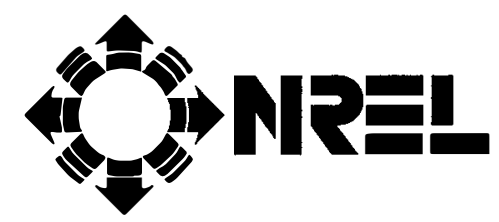

National Renewable Energy Laboratory A Division of Midwest Research Institute Operated for the U.S. Department of Energy Under Contract No. DE-AC02-83CH10093 


\title{
Processes for Pretreating Lignocellulosic Biomass: A Review
}

\author{
J. D. McMillan
}

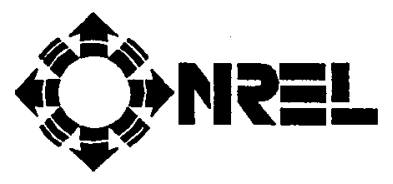

National Renewable Energy Laboratory (formerly the Solar Energy Research Institute) 1617 Cole Boulevard Golden, Colorado 80401-3393 A Division of Midwest Research Institute Operated for the U.S. Department of Energy under Contract No. DE-AC02-83CH10093

Prepared under task no. BF223732

November 1992 


\section{On September 16, 1991 the Solar Energy Institute was desi gnated a national laboratory, and its name was changed to the National Renewable Energy Laboratory.}

\section{NOTICE}

This report was prepared as an account of work sponsored by an agency of the United States government. Neither the United States government nor any agency thereof, nor any of their employees, makes any warranty, express or implied, or assumes any legal liability or responsibility for the accuracy, completeness, or usefulness of any information, apparatus, product, or process disclosed, or represents that its use would not infringe privately owned rights. Reference herein to any specific commercial product, process, or service by trade name, trademark, manufacturer, or otherwise does not necessarily constitute or imply its endorsement, recommendation, or favoring by the United States government or any agency thereof. The views and opinions of authors expressed herein do not necessarily state or reflect those of the United States government or any agency thereof.

Printed in the United States of America
$\quad$ Available from:
National Technical Information Service

National Technical Information Service
U.S. Department of Commerce

5285 Port Royal Road

Springfield, VA 22161

Price: Microfiche A01

Printed Copy $\mathrm{AO3}$

Codes are used for pricing all publications. The code is determined by the number of pages in the publication. Information pertaining to the pricing codes can be found in the current issue of the following publications which are generally available in most libraries: Energy Research Abstracts (ERA); Government Reports Announcements and Index (GRA and I); Scientific and Technical Abstract Reports (STAR); and publication NTIS-PR-360 available from NTIS at the above address. 


\section{Contents}

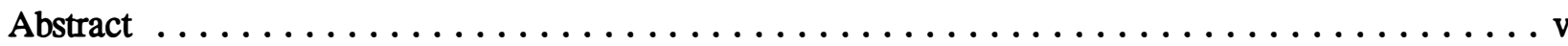

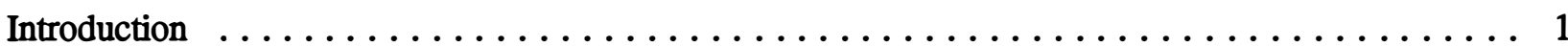

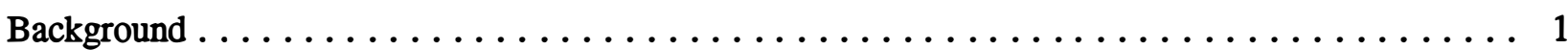

Composition and structure of biomass $\ldots \ldots \ldots \ldots \ldots \ldots \ldots \ldots \ldots \ldots \ldots \ldots \ldots \ldots$

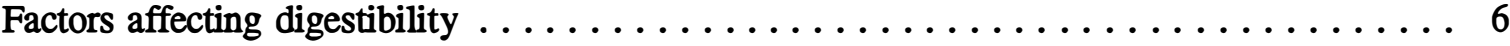

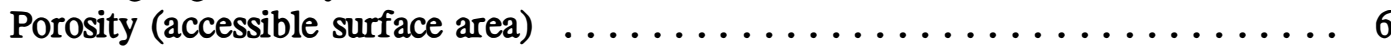

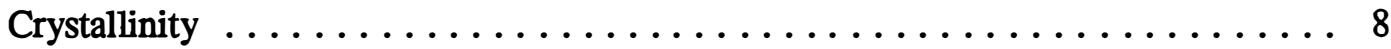

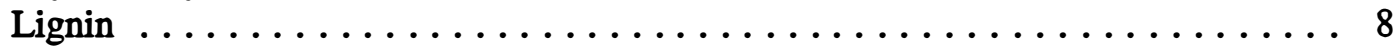

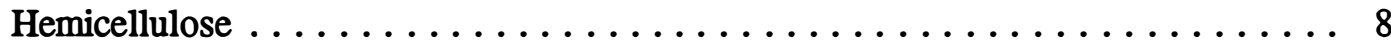

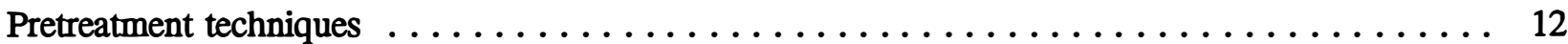

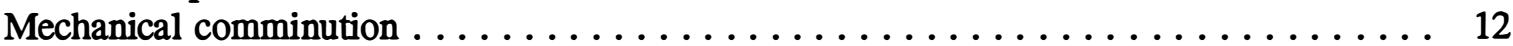

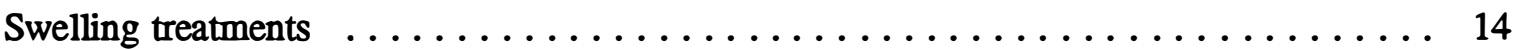

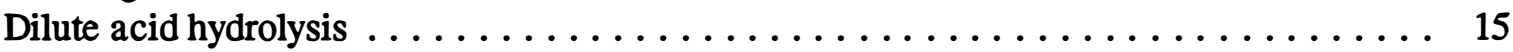

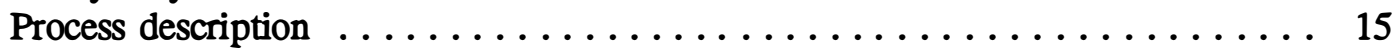

Kinetics ............................. 16

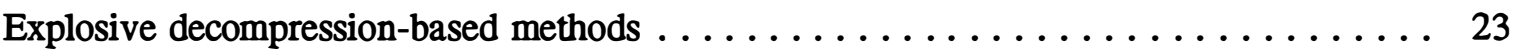

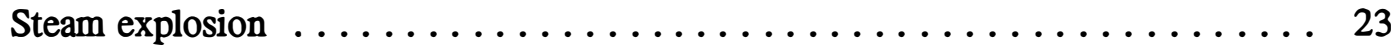

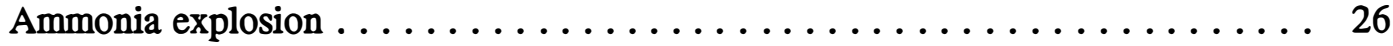

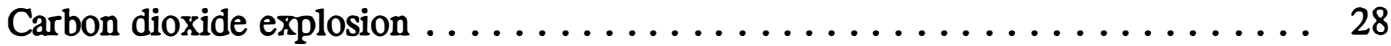

Alternative pretreatments . . . . . . . . . . . . . . . . . . . . . . . . 29

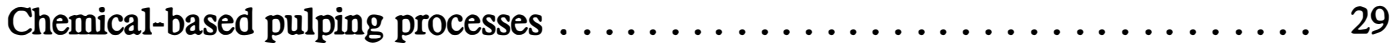

Supercritical fluid extraction . . . . . . . . . . . . . . . . . 29

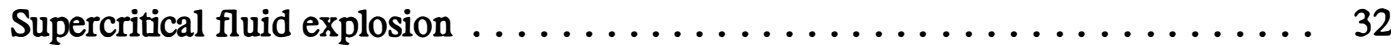

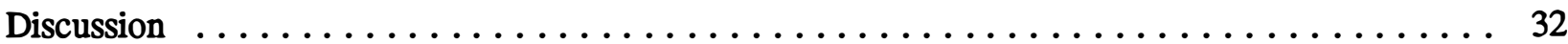

Development of improved pretreatment processes . . . . . . . . . . . . 32

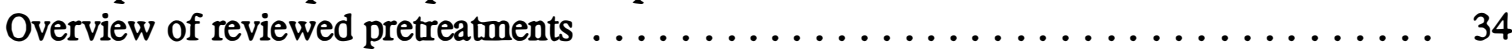

Mechanical comminution ....................... 34

Low-temperature alkali treatment .................... 34

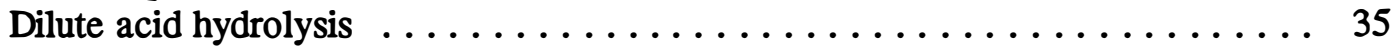

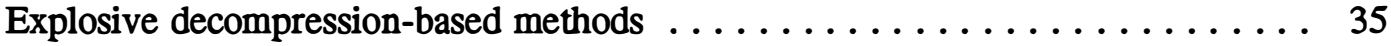

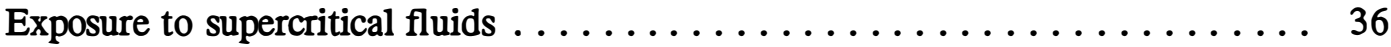

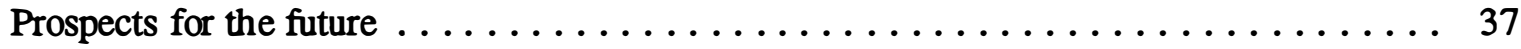

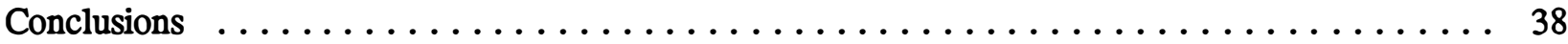

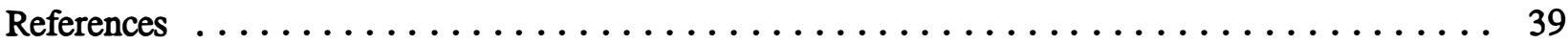




\section{Figures}

Page

Figure 1. Folding chain model of cellulose $\ldots \ldots \ldots \ldots \ldots \ldots \ldots \ldots \ldots \ldots \ldots$

Figure 2. Comparison of compositions of hard and soft wood $\ldots \ldots \ldots \ldots \ldots \ldots \ldots$

Figure 3a. Cross-section of spruce, a characteristic softwood, magnification $190: 1 \ldots \ldots$

Figure 3b. Cross-section of beech, a characteristic hardwood, magnification $300: 1 \ldots \ldots$

Figure 4a. Distribution of cellulose, hemicellulose, and lignin in the wood fiber cell wall $\ldots \ldots 7$

Figure $4 \mathrm{~b} . \quad$ Structure of the wood fiber cell wall $\ldots \ldots \ldots \ldots \ldots \ldots \ldots \ldots$

Figure 5. Digestibility of spruce sulfite pulps by a rumen inoculum $\ldots \ldots \ldots \ldots$

Figure 6. Digestibility as a function of percent delignification $\ldots \ldots \ldots \ldots \ldots$

Figure 7. Effect of lignin content on the in vitro digestibility of $\mathrm{NaOH}$-pretreated

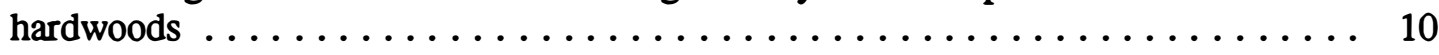

Figure 8. Digestibility of hardwood and softwood kraft pulps as a function of percent delignification. $\ldots \ldots \ldots \ldots \ldots \ldots \ldots \ldots \ldots \ldots \ldots \ldots \ldots \ldots$

Figure 9. Energy requirements for ball milling municipal solid waste $\ldots \ldots \ldots \ldots$

Figure 10. Maximum yield as a function of selectivity ratio for the sequential first

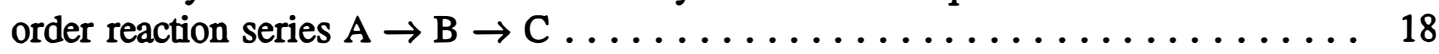

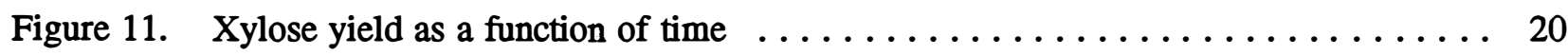

Figure 12. Total potential xylose, free xylose and decomposed xylose as a function

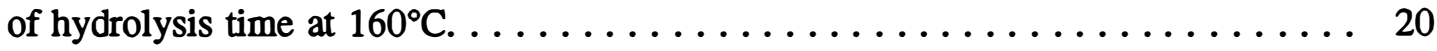

Figure 13 . Selectivity ratios as a function of temperature $\ldots \ldots \ldots \ldots \ldots \ldots \ldots$

Figure 14. Xylose yield as a function of time. $\ldots \ldots \ldots \ldots \ldots \ldots \ldots \ldots \ldots \ldots$

Figure 15 . Selectivity ratios as a function of temperature $\ldots \ldots \ldots \ldots \ldots \ldots \ldots \ldots \ldots$

Figure 16. Digestibility of water-insoluble fiber as a function of carbohydrate content $\ldots \ldots \ldots 26$ 


\section{Introduction}

The U.S. Deparment of Energy/National Renewable Energy Laboratory (NREL) Ethanol from Biomass Program is developing an economic process for the production of fuel ethanol from biomass. The generic term biomass here refers to any of the many inexpensive and abundant biogenic materials that can be used as substrates for renewable fuels and chemicals production. Biomass materials being considered by NREL for biofuels production include agricultural residues, herbaceous crops, hardwoods, and wastepaper.

The paramount objective in NREL's research program is to maximize the yield of ethanol from biomass substrates (Wright 1988). This is important because commodity fuels and chemicals production processes are substrate cost intensive, with feedstock costs representing roughly one half of total production costs (Dale 1985). Biomass substrate costs account for 50\%-60\% of total plant operating costs in a recent ethanol production plant technoeconomic analysis (Schell et al. 1990).

As described in greater detail in the section entitled Background, biomass materials exhibit a wide range of susceptibilities to both acidic and enzymatic hydrolysis because of differences in structure and lignocellulosic composition. Saccharification rates and yields on native lignocellulosics are low, however, and lignocellulosic materials must be pretreated in some manner prior to enzymatic hydrolysis to achieve high saccharification yields. Pretreatments typically involve a combination of mechanical, physical, and chemical processing steps.

As documented in the literature, current pretreatment technologies have advanced to the stage that agricultural residues and herbaceous crops can be saccharified with good yields, although pretreatment costs remain high. It has proven somewhat more difficult to achieve high saccharification yields with hardwoods using inexpensive pretreatment processes, but NREL's dilute acid process holds promise. It is currently not economical to pretreat and saccharify softwoods because of their more recalcitrant nature.

This paper reviews existing and proposed pretreatment processes. The focus is on the mechanisms by which the various pretreatments act and the influence of biomass structure and composition on the efficacy of particular pretreatment techniques. This analysis is used to identify pretreatment technologies and issues that warrant further research.

\section{Background}

\section{Composition and Structure of Biomass}

There are several types of biomass, including agricultural residues, herbaceous crops, and woody tree species. Agricultural residues and herbaceous crops include grasses, straws, legumes, corn, sorghum, and many other species. Woody biomass includes both deciduous (hardwood) and coniferous (softwood) tree species; Wenzl (1970) provides a comprehensive discussion of woody biomass structure and composition. Among the deciduous tree species are ash, aspen, basswood, beech, birch, cherry, cottonwood, elm, gum, maple, poplar, oak, sycamore, and a wide assortment of fruit and nut trees. Coniferous species include cypress, fir, hemlock, larch, pine, redwood, spruce, tamarack, eucalyptus, evergreen, and others.

Woody and herbaceous types of biomass are composed primarily of carbohydrates and lignin. Although wood is generally considered to be only lignocellulosic material, it also contains other so-called extraneous materials. The type and amount of extraneous components vary widely among biomass species and strongly influence resistance to enzymatic attack and/or thermo-chemical-mechanical pretreatments. Extraneous materials are classified as extractives or nonextractives based on their solubilities in water and organic solvents (Fan et al. 1982). Extractive components in woody biomass include mainly terpenes 
(isoprene alcohols and ketones), resins (fats, fatty acids, alcohols, resin acids, and phytosterols), and phenols (primarily tannins). Nonextractives are mainly inorganic components such as alkali earth carbonates and oxalates, as well as some non-cell-wall materials like starches, pectins, and proteins. Nonextractive silica crystals are abundant in grasses and straws, but not in trees (Fan et al. 1982).

The carbohydrate portion of biomass is made up of holocellulose, composed of the high molecular weight polysaccharides cellulose and hemicellulose. Cellulose is the main component of wood, representing about $50 \%$ of the dry weight of wood. Cellulose is a linear polymer of anhydro D-glucose units connected by $1,4 \beta$-glucosidic bonds. Native cellulose exists as a fibrous crystal with the so-called Cellulose-I lattice structure. However, Cellulose-I is easily converted to Cellulose-II by physicochemical treatments, such as intercrystalline swelling; mercerized or regenerated cellulose has a crystalline lattice structure known as Cellulose-II. Three other less commonly enountered stable lattice structures are also known: Cellulose-III, $-\mathrm{V}$, and $-\mathrm{X}$ (Chang et al. 1981).

Cellulose crystals (Cellulose-I or -II) are organized into compacted crystallite microfibrils measuring $35 \times 40 \AA$ in width and about $500 \AA$ in length, having an average degree of polymerization (DP) of about 1000 (in number average molecular weight units) (Chang et al. 1981). The accepted view is that of the folding chain model of cellulose crystal structure in which segments of linear cellulose polymer are folded back and forth along the major axis of the fibrillar crystallite to make up individual microfibrils, as depicted in Figure 1 reproduced from Chang et al. (1981).

Hemicelluloses are shorter chain, amorphous polysaccharides of cellulans and polyuronides. Cellulans are polymers made up of hexosans (mannan, galactan, and glucosan) and pentosans (xylan and araban). Polyuronides are similar to cellulans, but contain appreciable quantities of hexuronic acids as well as some methoxyl, acetyl, and free carboxylic groups. Chum et al. (1985) provide the following details regarding the hemicellulose composition of woody biomass species. Hardwoods are $23 \%-35 \%$ hemicellulose, composed of $20 \%-30 \%$ xylan and 3\%-5\% glucomannan; xylan represents $80 \%-91 \%$ of total hardwood hemicellulose. Softwoods are $24 \%-36 \%$ hemicellulose, composed of $8 \%-14 \%$ xylan and $16 \%-22 \%$

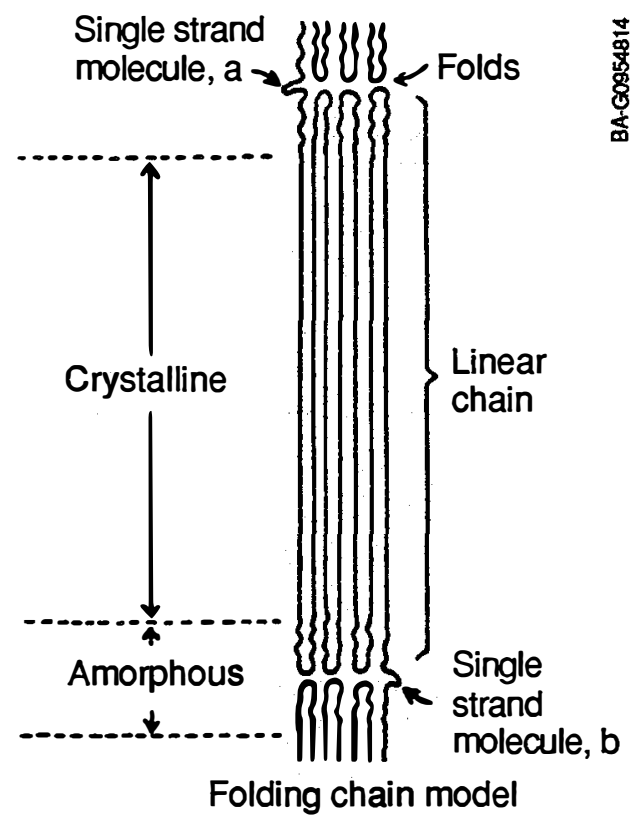

Figure 1. Folding chain model of cellulose. (After Chang et al. 1981) 
glucomannan; xylan represents only $27 \%-47 \%$ of total softwood hemicellulose. The xylan in softwoods is not acetylated and contains arabinose sidegroups. Softwood glucomannan is acetylated and contains galactose sidegroups.

The amount of lignin in coniferous softwoods (25\%-35\%) is appreciably greater than in deciduous hardwoods (18\%-25\%), straws (10\%-20\%), and agricultural residues (10\%-15\%) (Fan et al. 1982; Hinman et al. 1990). Lignin is composed of polymerized phenylpropanoic acids in a complex three-dimensional structure. Individual monomers are held together by ether and carbon-carbon bonds (Fan et al. 1982). Polymerization occurs by a free radical mechanism; therefore, the structure of lignin is random. Hemicellulose is considered to act as the glue between lignin and cellulose components. Hence, hemicellulose and lignin are envisioned to form an effective sheath around cellulose fibers, which adds structural strength to the wood matrix. It is not clear, however, if covalent bonds exist between hemicellulose and lignin. Figure 2 from Fan et al. (1982) illustrates the differences in composition between trembling aspen (hardwood) and white spruce (softwood).

Coniferous (soft) woods are composed primarily of tracheid fiber cells, which are elongated, tubelike structures with closed ends that are square in cross section. As Figure $3 \mathrm{a}$ shows, earlywood fibers in softwoods have a pronounced lumen and are thin-walled, whereas latewood fibers have thicker walls and smaller lumens. Deciduous (hard) woods, on the other hand, are composed of vessels and sclerenchyma or librilform fiber cells. Vessels are long, continuous tubes that serve as a conduit for water and, as shown in Figure 3b, have a much larger diameter than the individual fiber cells. The significant difference

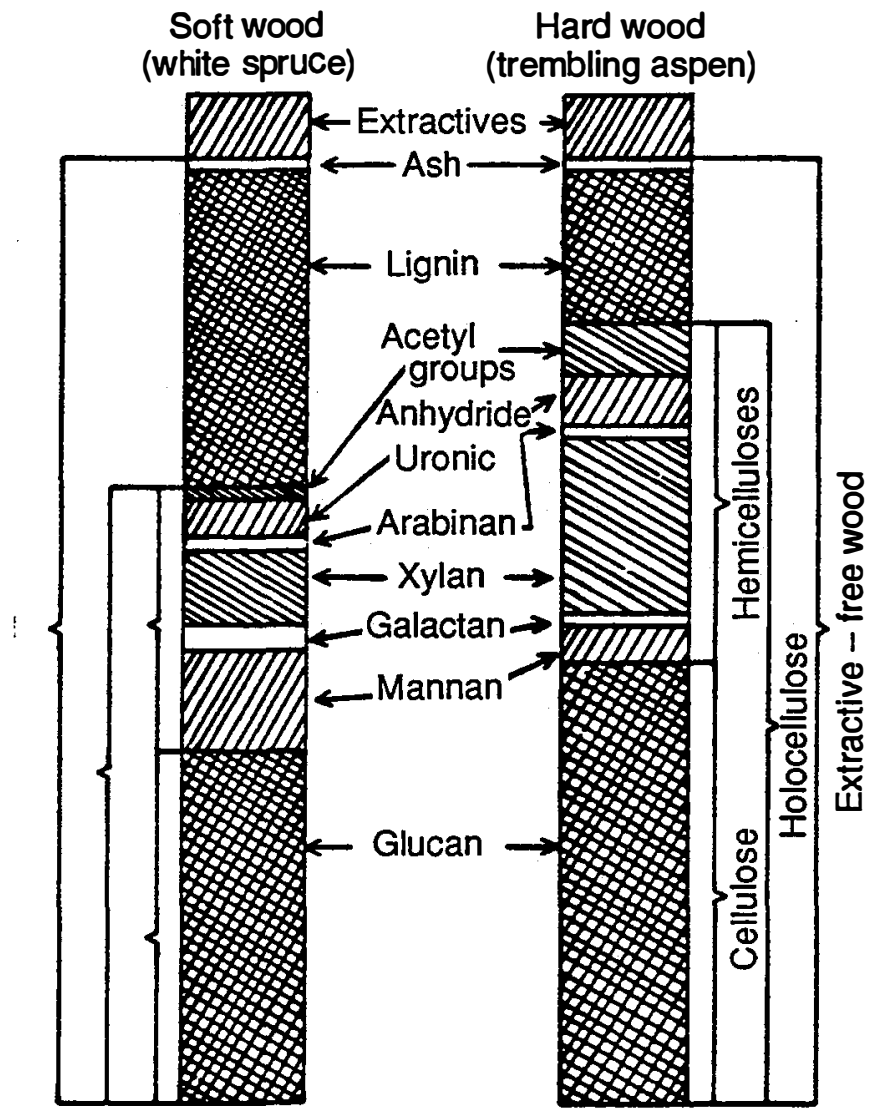

递

Figure 2. Comparison of compositions of hard and soft wood. (Reprinted with permission from Fan et al. 1982, Adv. Biochem. Eng. 23; 157-187; Springer-Verlag: NY) 


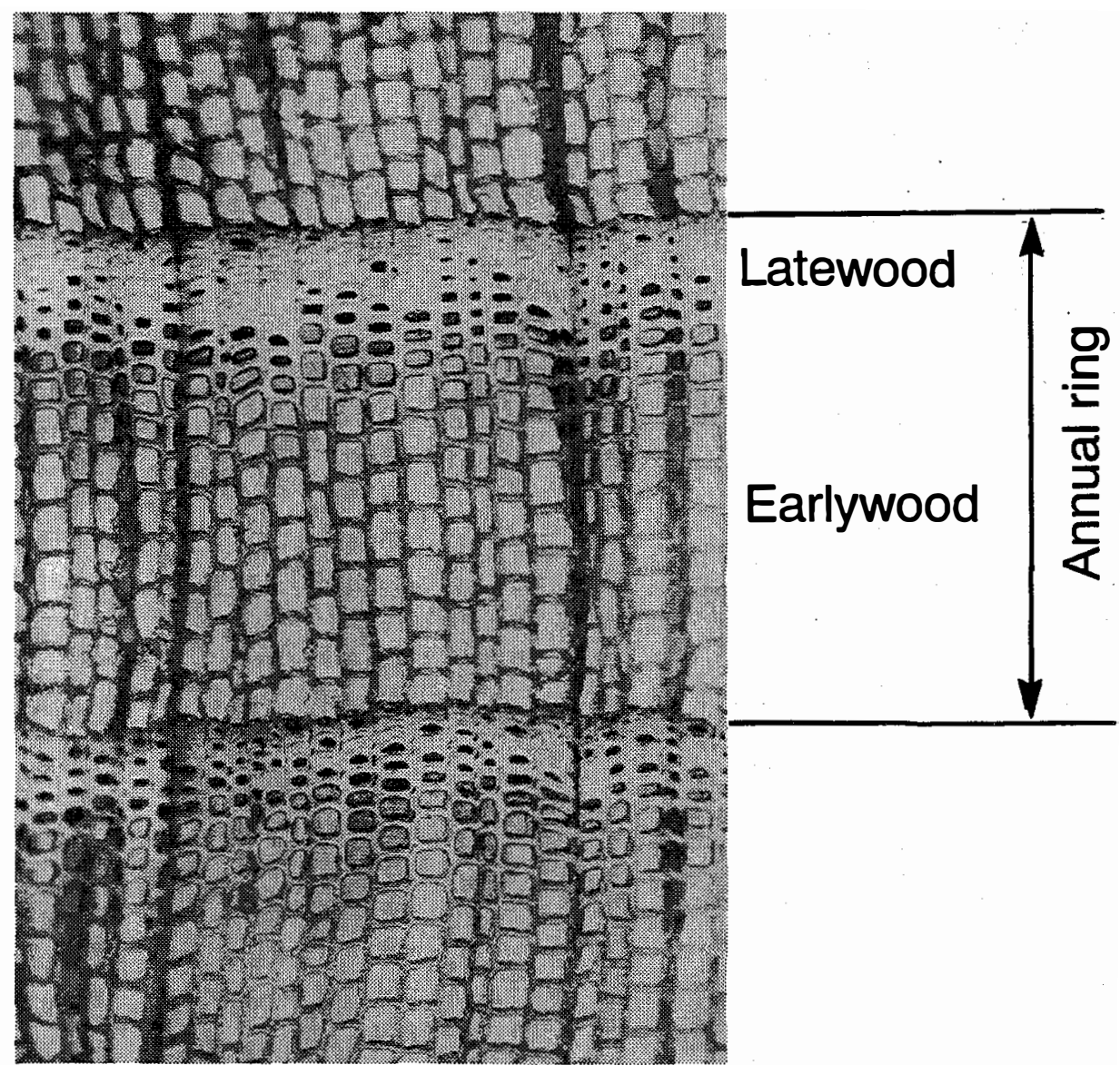

Figure 3a. Cross-section of spruce, a characteristic softwood, magnification 190:1. (Courtesy of Cellulose Attisholz) 


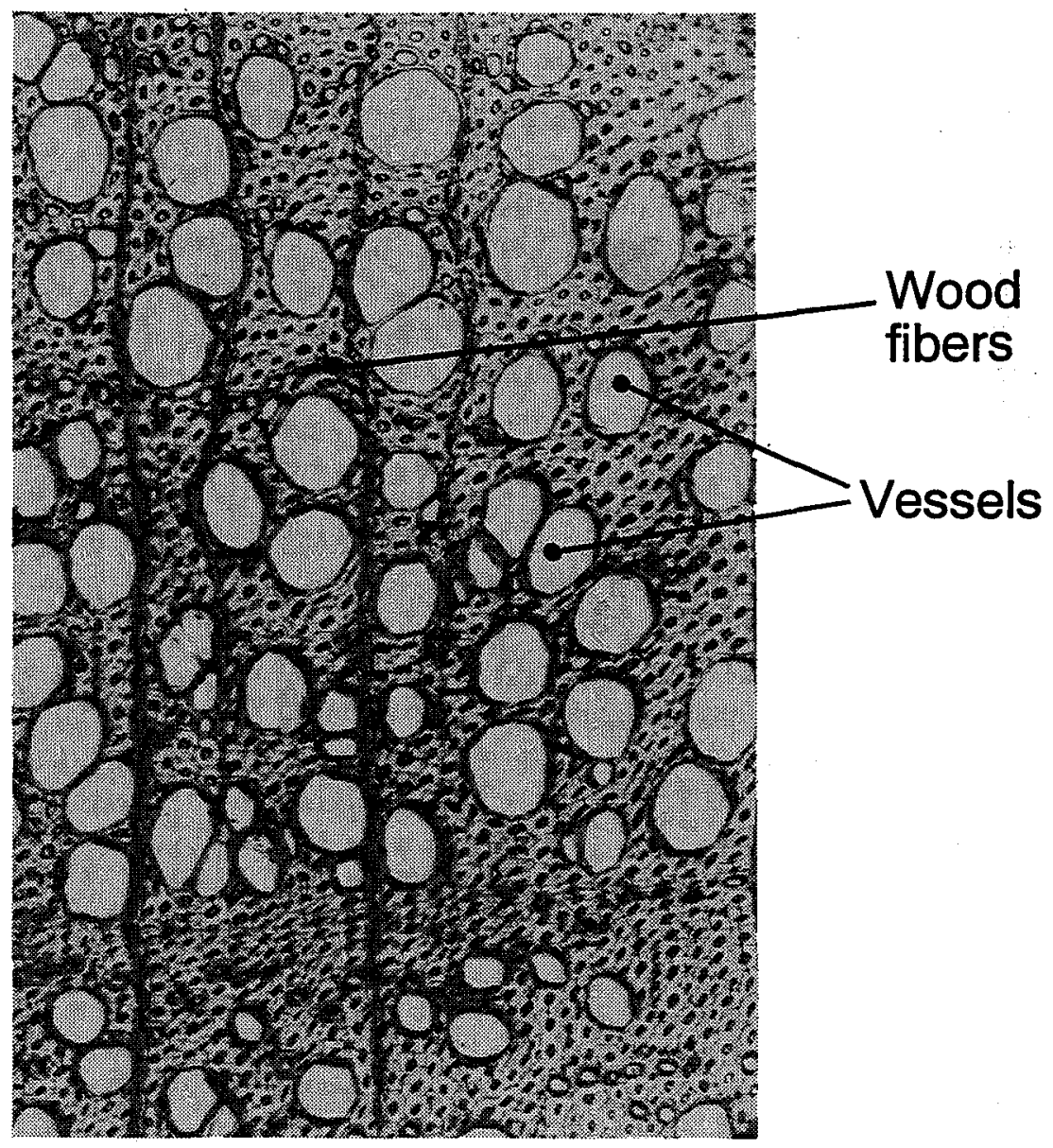

Figure 3b. Cross-section of beech, a characteristic hardwood, magnification 300:1. (Courtesy of Cellulose Attisholz) 
in the structure of coniferous and deciduous woods, coupled with the higher lignin content of coniferous woods, explains the dramatic differences in susceptibility to various pretreatment techniques that exist between hardwood and softwood species. The presence of vessels in the hardwoods permits greater penetration of heat, chemicals, and enzymes into the wood matrix, making hardwoods easier to pretreat. Similarly, differences in lignocellulosic structure (and composition) cause profound differences in susceptibility to pretreatment and enzymatic hydrolysis to exist among agricultural residues, herbaceous crops, hardwoods, and wastepaper.

The distribution of cellulose, hemicellulose, and lignin within a typical wood fiber cell wall is shown in Figures 4a and 4b from Fan et al. (1982). These diagrams vividly depict the "lignin seal" that effectively exists at the outer periphery of individual wood fibers. The outer portion of the compound middle lamellae is almost entirely lignin. The percentage of lignin in the lignocellulosic matrix decreases with increasing distance into the fiber cell wall, such that the percentages of lignin in the primary wall and in the S1 layer of the secondary wall are much higher than in the S2 and S3 sections of the secondary wall.

\section{Factors Affecting Digestibility}

The digestibility of a lignocellulosic substrate is a measure of the ease with which an organism (ruminant animal or cellulolytic microorganism) or enzyme mixture is able to saccharify holocellulose to digestible sugars, primarily glucose. Lignocellulosic materials are only partially digestible in their native form, and there is considerable interest in increasing their digestibility so that agricultural and forestry residues can be used as inexpensive feeds or feed supplements for ruminants. The efficacy of using pretreatments to improve the digestibility of lignocellulosic biomass has been recognized at least since 1919, when Beckmann patented an $\mathrm{NaOH}$ alkali pretreatment for improving the in vitro digestibility of straws by ruminants (Millett et al. 1976).

Numerous pretreatment processes have been investigated since the development of the Beckmann process, and considerable research has been conducted to establish the key factors influencing enzymatic hydrolysis rates of lignocellulosics. Experimental studies have demonstrated that the digestibility of a lignocellulosic material strongly depends on both its structure and its composition. Large differences are observed in the in vitro (and in vivo) digestibility of pretreated and native lignocellulosic materials, both within and among species. Major factors that have been identified to influence the reactivity of a lignocellulosic material are hemicellulose content, lignin content, cellulose fiber crystallinity, and material porosity (or accessible surface area). Prevailing hypotheses regarding the influence of these key factors are outlined in the following paragraphs.

\section{Porosity (Accessible Surface Area)}

Researchers have discussed at length how many structural and compositional factors are important determinants of enzymatic digestibility. Stone et al. (1969) put forward the hypothesis that the initial rate of hydrolysis is a function of the accessible surface area of cellulose in a lignocellulosic material, and that the rate increases with increasing (effective) coverage of cellulase enzyme. Quantifying how the accessible surface area of a material changes as a function of pretreament, however, is difficult. Studies to date have used nitrogen adsorption, mercury porosimetry, dye adsorption (Poots and McKay 1979; Hradil et al. 1988) and solute exclusion (Stone et al. 1969; Burns et al. 1989; Converse et al. 1990) to quantify surface area. Surface area estimates indicate that accessible surface area increases following pretreatment, but there is disagreement as to how much. An important issue is how lignin affects accessible surface area. Cellulase is known to bind to lignaceous residues (Ooshima et al. 1990), and the presence of lignin may also physically restrict or otherwise block enzymatic binding to the lignocellulosic surface. 


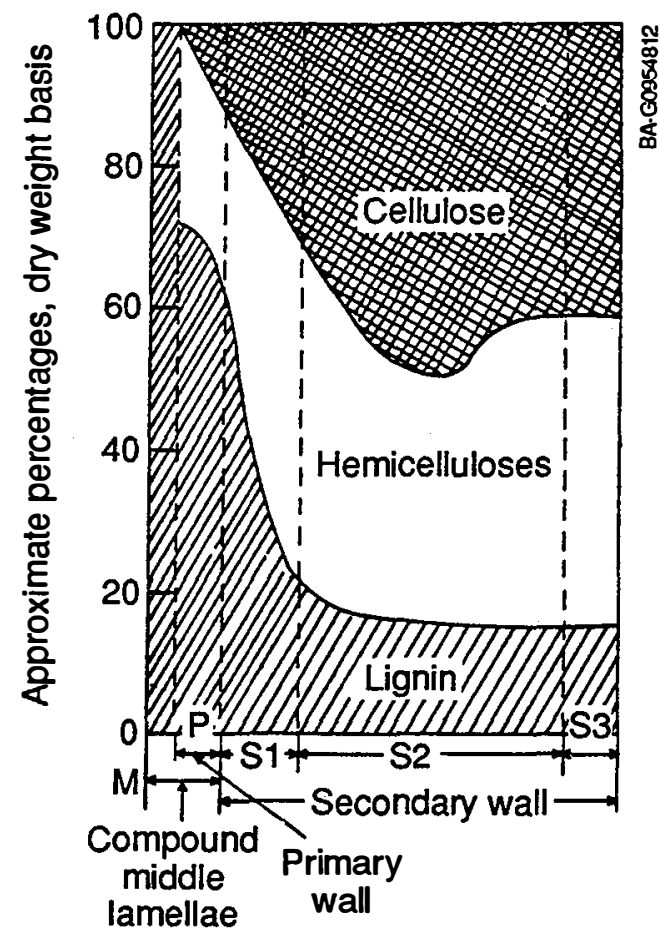

Figure 4a. Distribution of cellulose, hemicellulose, and lignin in the wood fiber cell wall. (Reprinted with permission from Fan et al. 1982, Adv. Biochem. Eng. 23; 157-187; Springer-Verlag: NY)
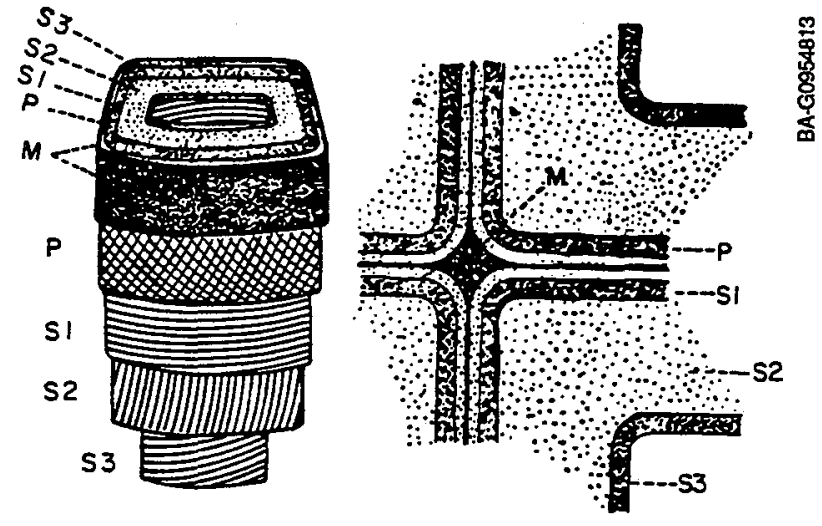

Figure 4b. Structure of the wood fiber cell wall. (Reprinted with permission from Fan et al. 1982, Adv. Biochem. Eng. 23; 157-187; Springer-Verlag: NY) 


\section{Crystallinity}

Many researchers argue that whereas the amount of enzyme that binds is determined by the accessible surface area, the hydrolysis rate of the adsorbed enzyme is determined by the extent of cellulose crystallinity (Fan et al. 1980; Fan et al. 1982). This hypothesis is supported by the fact that size reduction does little to increase the exposed surface area of cellulose because of the high aspect (length to width) ratio of the fibers, and thus presumably has little effect on the accessible surface area. Thus the DP of the cellulose (some refer to it as the ratio of easily hydrolyzed amorphous to refractile crystalline cellulose) is thought by some to determine the hydrolysis rate of adsorbed enzyme. Still others, like Schurz (1986), observe no change in crystallinity during hydrolysis, concluding that hydrolysis occurs by an "all or nothing" process; differences in rate are attributed to differences in the type or quality of surface adsorption.

\section{Lignin}

It is well documented that the digestibility of lignocellulosic materials (hardwoods, softwoods, and herbaceous crops) varies, in general, in negative proportion to lignin content; saccharification rates of alkali-pretreated hardwood increase with decreasing lignin content (Millett et al. 1976). Figures 5 and 6 show data from Stone et al. (1969) on the digestibility of softwoods as a function of the amount of lignin removed by sulfite pulping. Figures 7 and 8, taken from Millett et al. (1976), depict the effect of lignin content on the in vitro digestibility of $\mathrm{NaOH}$-treated hardwoods and lraft pulped wood species, respectively.

Chang et al. (1981) observe that lignin can only interfere with hydrolysis if it blocks access to cellulose fibers or irreversibly binds cellulase or $\beta$-glucosidase. And recall that Ooshima et al. (1990) showed that cellulase enzyme binds to lignaceous residue. Tarkow and Fiest (1969), however, observe that the location and nature of carbohydrate-lignin bonding also strongly influences digestibility, since materials with similar lignin contents may have very different digestibilities (e.g., jute versus hay).

\section{Hemicellulose}

Dilute acid pretreatment results clearly show that removal of hemicellulose improves the digestibility of hardwood species (Grohmann et al. 1985). The results of Burns et al. (1989) and Converse et al. (1990) suggest that hemicellulose removal increases porosity and the specific surface area accessible to enzymes.

There is still considerable controversy about which factors most influence enzymatic hydrolysis. Many researchers, including Fan et al. (1982) and Lynd (1990), believe that the external surface area and reactivity of a treated material determine the rate of enzymatic hydrolysis. This theory ascribes lower than theoretical ultimate yields to highly crystalline regions of cellulose that are impervious to enzymatic attack. Other researchers hypothesize that structural features control the extent to which a lignocellulosic material is accessible to enzymatic attack. Stone et al. (1969), Grethlein (1985), and K. Grohmann (1990) believe that the porosity of the lignin-hemicellulose sheath controls enzyme accessibility and hydrolysis rates. This view attributes low ultimate yields to cellulose regions that are inaccessible to enzymes. It is difficult to determine which of these hypotheses is correct since the relative importance of enzyme accessibility and cellulose crystallinity will vary depending on the system being examined. Examples can probably be found in which either accessible surface area or reactivity controls the rate of hydrolysis. However, susceptibility to enzymatic hydrolysis is generally affected by both accessible surface area and reactivity. 


\begin{tabular}{ccc} 
Yield & \% Cellulose & $\begin{array}{c}\text { \% of Total Lignin } \\
\text { Removed }\end{array}$ \\
\hline 100.0 & 54.1 & 0 \\
96.4 & 58.2 & 2 \\
90.1 & 62.0 & 11 \\
81.3 & 66.2 & 16 \\
70.0 & 73.5 & 36 \\
62.6 & 79.9 & 54 \\
57.0 & 88.0 & 71 \\
52.5 & 93.4 & 81 \\
\hline
\end{tabular}

${ }^{a} \mathrm{Kl}$ ason plus U.V. lignin

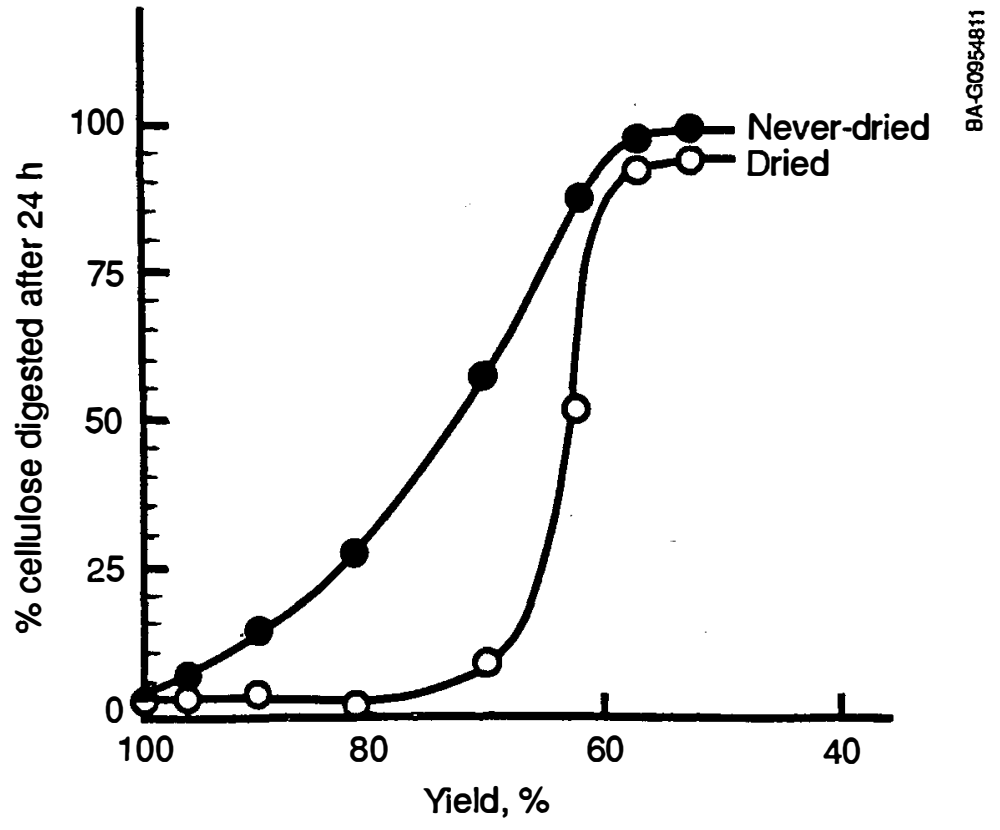

Figure 5. Digestibility of spruce sulfite pulps by a rumen inoculum. The table shows composition of pulps as a function of pulping yield. (Reprinted with permission from Stone et al. 1969, Adv. Chem. Ser. (95):219-241. Copyright (1969) American Chemical Society) 


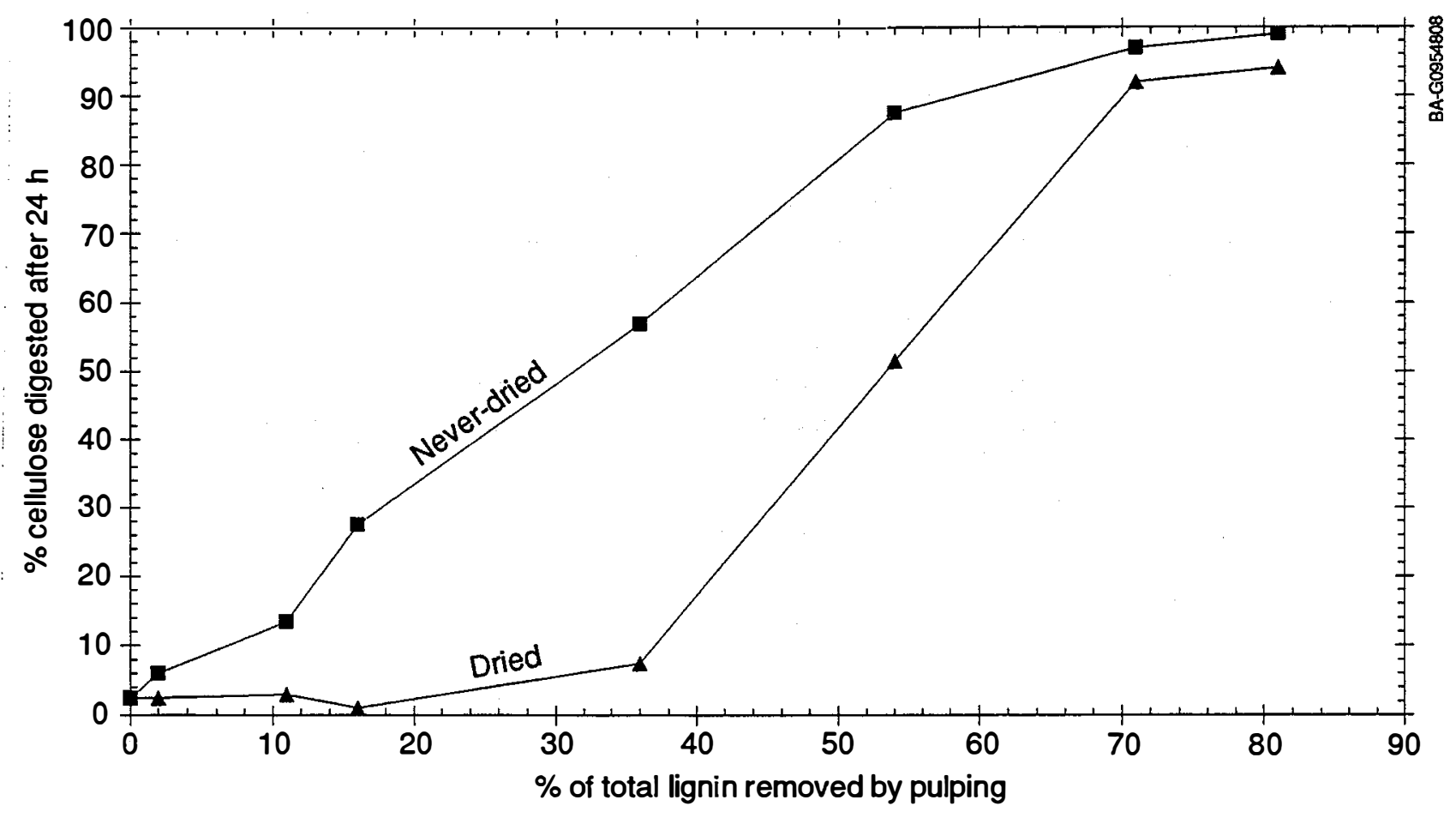

Figure 6. Digestibility as a function of percent delignification. Data are from Stone et al. (1969) for black spruce pulped by the sulfite process. Values interpolated from Figure 5. Adv. Chem. Ser. (95): 219-241. Copyright (1969) American Chemical Society

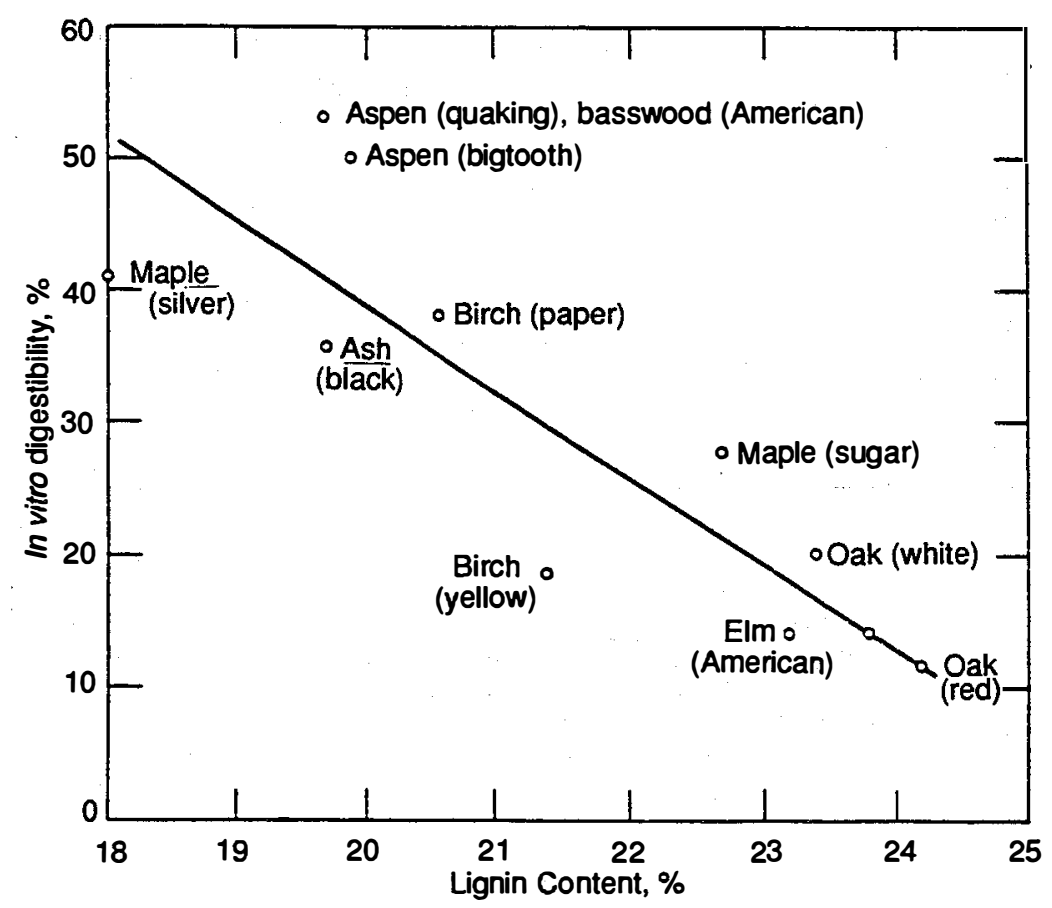

Figure 7. Effect of lignin content on the in vitro digestibility of $\mathrm{NaOH}$-pretreated hardwoods. Adjacent to individual data points are the names of the hardwood species to which the point refers. (Adapted from Millett, et al. 1976, Biotech. Bioeng. Symp. 6: 125-153. Copyright $^{\circ}$ 1976. John Wiley \& Sons, Inc.) 
Degree of Delignification Required to Attain $60 \%$ in vitro Digestibility

\begin{tabular}{lcc}
\hline Wood & $\begin{array}{c}\text { Required } \\
\text { delignification } \\
\%\end{array}$ & $\begin{array}{c}\text { Lignin in } \\
\text { original wood } \\
\%\end{array}$ \\
\hline White birch & 25 & 20 \\
Red Oak & 35 & 23 \\
Red pine & 65 & 27 \\
Douglas fir & 73 & 32 \\
\hline
\end{tabular}

${ }^{\text {a } B a s e d}$ on original wood.

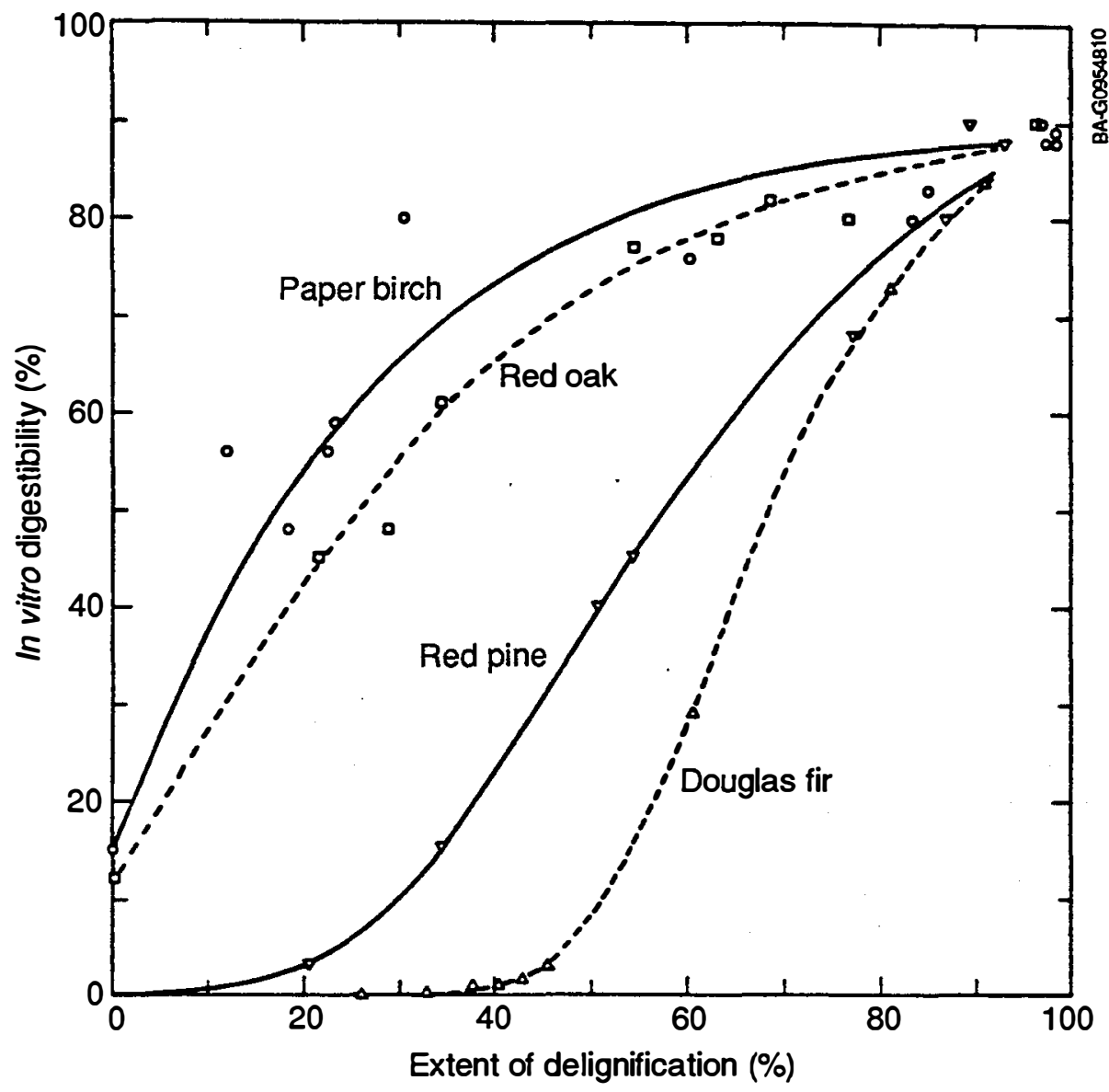

Figure 8. Digestibility of hardwood and softwood kraft pulps as a function of percentage of delignification. (Reprinted with permission from Millett, et al. 1976, Biotech. Bioeng. Symp. 6: 125-153. Copyright 1976. John Wiley \& Sons, Inc.) The table shows the degree of delignification necessary to achieve $60 \%$ in vitro digestibility. 


\section{Pretreatment Techniques}

As discussed previously, the two factors most widely believed to control enzymatic digestibility are the accessible surface area and the crystallinity of the cellulosic fraction. Effective pretreatment processes must therefore increase the degree to which the cellulosic fraction of the lignocellulosic material is susceptible to enzymatic attack and/or decrease the extent of cellulose microfibril crystallinity. Increased accessibility of cellulose enables more enzyme to bind to cellulose fiber surfaces, whereas decreased crystallinity increases the reactivity of cellulose, i.e., the rate at which bound enzyme hydrolyzes glycosidic linkages.

The primary goal of pretreatment is to maximize the formation of sugars or the ability to form sugars by subsequent enzymatic hydrolysis of the carbohydrate fraction of the (pretreated) biomass. It is imperative to achieve high yield and minimize the breakdown of sugars into decomposition products. The rate of formation of sugars relative to their rate of destruction must be maximized to achieve a high-yield pretreatment. Cellulose and hemicellulose hydrolysis and degradation are all pseudo first-order processes. As shown in Equation (1), the real challenge of pretreatment is to achieve high selectivity by maximizing the ratio of the rate constants, $k_{i 1} / k_{i 2}$, where the subscript $i$ refers to rate constants for either cellulose (c) or hemicellulose $(\mathrm{h})$ hydrolysis.
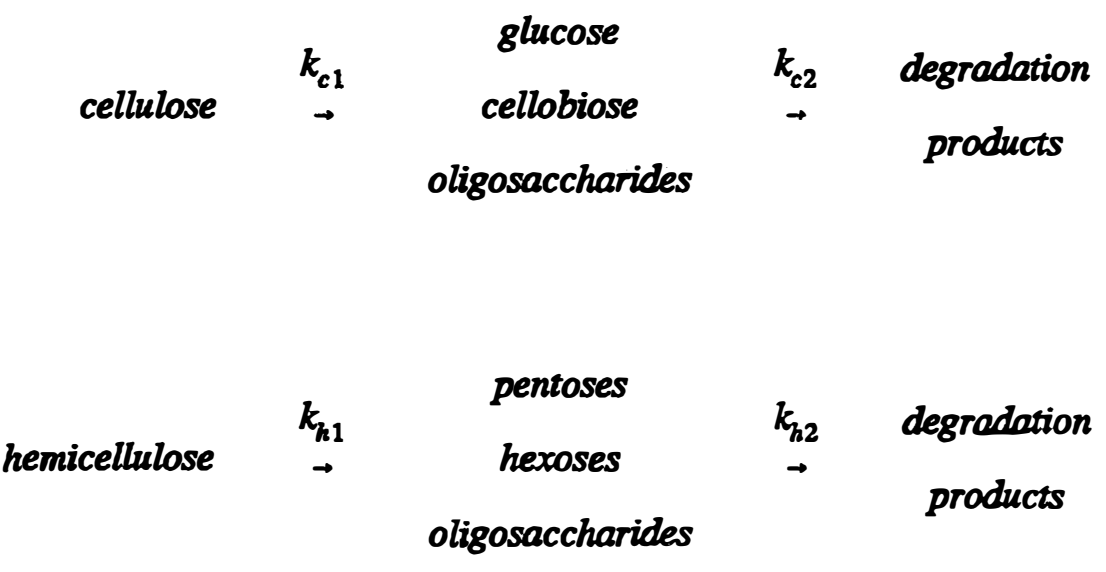

Many pretreatments utilize catalyzed, high-temperature, short-residence-time processes to achieve high selectivity, as discussed in the section on acid hydrolysis pretreatment.

Pretreatment methods include comminution, alkali swelling, acid hydrolysis, steam and other fiber explosion techniques, many alcohol and chemical-based pulping and/or delignification processes, exposure to supercritical fluids, and irradiation. Discussions of these pretreatments are provided in the following sections; reviews of the various approaches to pretreatment are also provided by Millett et al. (1976), Chang et al. (1981), Lin et al. (1981), Fan et al. (1982), and Dale (1985).

\section{Mechanical Comminution}

All pretreatment processes involve an initial mechanical step in which the biomass is comminuted by a combination of chipping, grinding, and/or milling. Steam explosion processes use explosive decompression to significantly reduce the particle size of coarsely chipped biomass, whereas other pretreatment processes typically employ a secondary grinding or milling step to further reduce the particle size of chipped biomass. Chipped biomass has a characteristic dimension of $1 \mathrm{~cm}$ to $3 \mathrm{~cm}$, in comparison to milled or ground material, which ranges from $0.2 \mathrm{~mm}$ to $2.0 \mathrm{~mm}$. 
Datta (1981) used the data of Nystrom (1975) to estimate the energy requirements for ball milling of municipal solid wastes relative to their total energy content. As Figure 9 shows, power requirements increase rapidly with decreasing particle size. More than $25 \%$ of the total energy of the substrate is required to mill to particle sizes below $150 \mu \mathrm{m}$.

Himmel et al. (1985) measured the energy required to mill coarse biomass chips into fine particles, and observed that energy requirements are strongly substrate-dependent. The specific milling energy required to produced 0.25 -in. or smaller particles, for example, was about two-and-a-half-fold higher for aspen wood chips than for com cobs; for particles 0.50 -in. or smaller, the difference was greater than eightfold.

Much of the pretreatment research reported in the literature uses 60 mesh $(250 \mu \mathrm{m}=0.25 \mathrm{~mm})$ wood flour as a substrate (e.g., the extensive work of Grethlein et al.). The energy requirements for milling biomass particles to such small sizes may be prohibitively expensive for low-profit-margin, high-volume, industrialscale pretreatment processes (Millett et al. 1976).

Some researchers have concluded that milling processes, especially vibratory ball milling, increase the reactivity of cellulose, in addition to increasing the external surface area. Millett et al. (1976) report that vibratory ball milling breaks down the crystallinity of cellulose to an extent that complete digestion of milled biomass is possible. Fan et al. (1982) also conclude that ball milling causes a reduction in cellulose crystallinity, although they observe that the efficacy of this approach is strongly dependent on the nature of the material being milled. They cite the additional advantage that ball-milled material is often more dense than the native material and can therefore be slurried up to a higher solids loading.

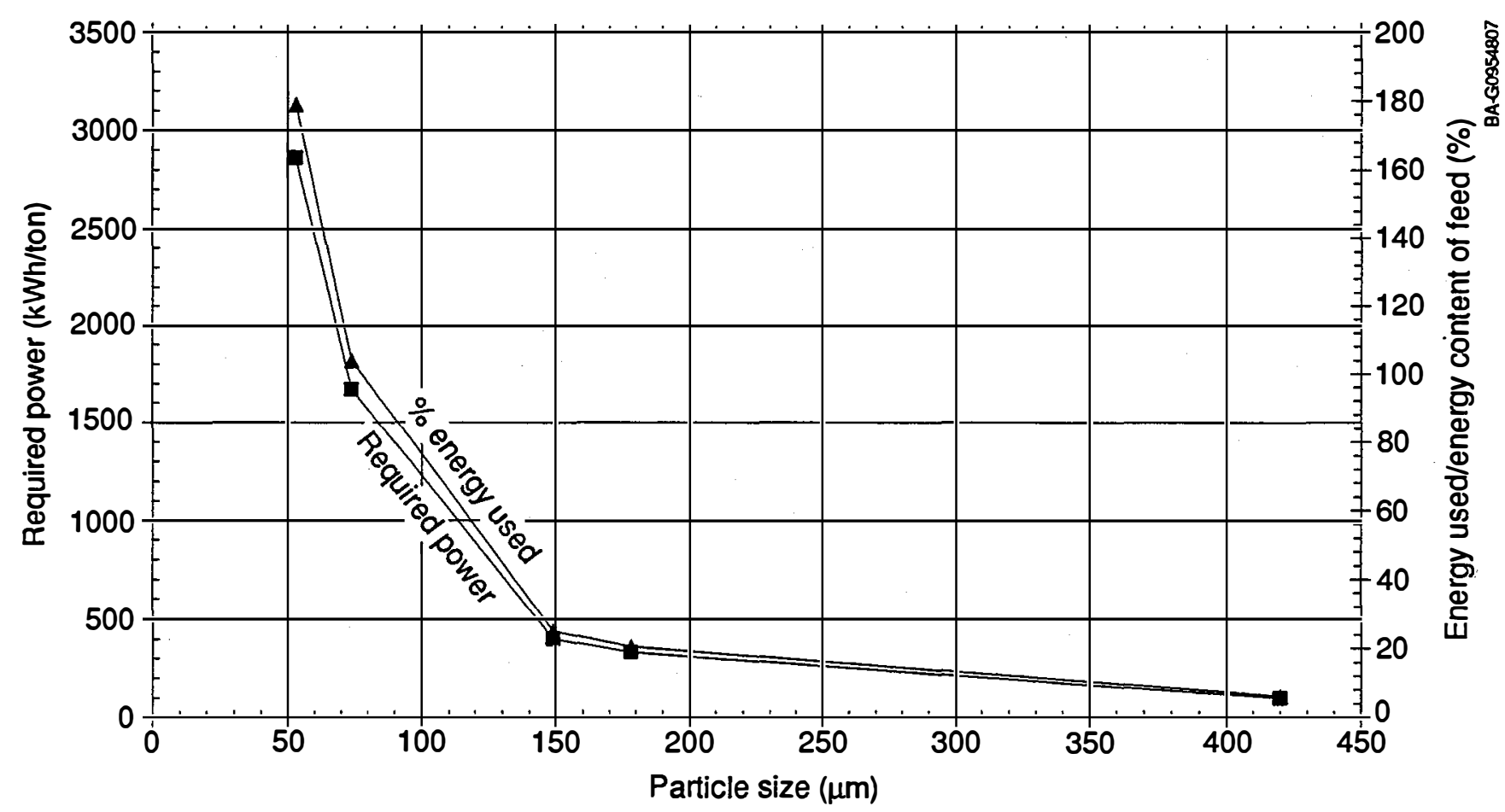

Figure 9. Energy requirements for ball milling municipal solid waste. (After Datta 1981) 


\section{Swelling Treatments}

The degree to which a lignocellulosic material swells in the presence of water is increased by treating the material with a swelling agent. Increased swelling is observed to correlate with increased digestibility. Certain swelling agents such as $\mathrm{NaOH}$, amines, and anhydrous $\mathrm{NH}_{3}$ cause limited swelling. Other chemicals, such as concentrated acids like $\mathrm{H}_{2} \mathrm{SO}_{4}$ and $\mathrm{HCl}$ (the older European wood hydrolysis processes used $70 \%-75 \% \mathrm{H}_{2} \mathrm{SO}_{4}$ or fuming [40\%] $\mathrm{HCl}$ ) or high concentrations of cellulose solvents like cupran, cuen, or cadoxen, totally dissolve (or hydrolyze) holocellulose (Sherrard and Kressman 1945; Lin et al. 1981). Although they are powerful solubilization agents for cellulose, however, concentrated acids and metal chelate cellulose solvents are not being used for large-scale pretreatment processes, apparently because of their toxic, corrosive, and hazardous nature, and because of high recovery costs (Millett et al. 1976).

Swelling literature recognizes the difference between intercrystalline and intracrystalline swelling. Ideally, swelling pretreatment causes intracrystalline swelling in which the crystalline structure is modified or disnupted by the penetration of the chemical solute into the crystal structure. As discussed previously, many researchers believe that cellulose crystallinity is the major determinant of saccharification rates. This may be particularly true for chemical hydrolysis processes because of the smaller molecular size of chemical catalysts relative to enzymes. Lignin content, hemicellulose content, and porosity (surface accessibility), however, are also important factors in hydrolysis processes.

Millett et al. (1976) report that alkali pretreatment by dilute $\mathrm{NaOH}$ soaking has been widely used to improve the digestibility of lignocellulosics by ruminants. The digestibility of various lignocellulosic materials following alkali pretreatment is highly correlated with lignin content. The efficacy of dilute $\mathrm{NaOH}$ pretreatment is higher for straws than for hardwoods. As Figure 7 shows, for hardwoods effectiveness is increased as lignin content decreases from $24 \%$ to $18 \%$. No effect of dilute $\mathrm{NaOH}$ pretreatment is observed for softwoods in which the lignin content is $26 \%-35 \%$.

$\mathrm{NaOH}$ treatment followed by water washing yields a lignocellulosic residue with a polyionic character, since sodium ions remain to act as a counter charge to carboxylate ions. This polyionic character promotes swelling relative to $\mathrm{NaOH}$ treatment followed by acid washing in which the sodium ions are displaced by protons.

Tarkow and Feist (1969), building on earlier work by Wang et al. (1967), postulated that the mechanism of alkali pretreatment is saponification of intermolecular ester bonds crosslinking xylan hemicelluloses and other polymeric materials, such as lignin or other hemicelluloses (or cellulose proper?). Saponification of the uronic ester linkages in 4-O-methyl-D-glucuronic acids pendant along the xylan chain readily occurs in the presence of alkali. (So does saponification of acetyl groups pendant along the xylan backbone, which is likely to have an autocatalytic effect on hemicellulose hydrolysis when it occurs.) Apparently, the removal of crosslinks in the lignocellulose structure permits swelling beyond normal water-swollen dimensions. Increased swelling results in a phase change in cellulose crystal structure from Cellulose-I to Cellulose-II (Chang et al. 1981) or Cellulose-III (Millett et al. 1976; Lin et al. 1981; Fan et al. 1982).

Tarkow and Feist (1969) used a solute exclusion technique to characterize the pore size of alkali-treated wood. When they used untreated wood, they observed a molecular weight cutoff at about polyethylene glycol (PEG) 3000, which they estimated corresponded to a protein molecular weight cutoff of roughly 30,000 Daltons. This contrasted with an estimated protein MW cutoff of 40,000-50,000 for $\mathrm{NaOH}$-treated wood. Their results indicate that intraparticle porosity and channel size are increased by dilute alkali treatment.

As noted by Wang et al. (1967), gaseous or aqueous ammonia also cause swelling by a similar mechanism. At ambient conditions, longer reaction times are generally required; for comparable reaction 
times, digestibility is lower following ammonia treatment than it is following $\mathrm{NaOH}$ treatment. In ammonia alkali treatment, instead of saponification of an ester bond to yield an ionized carboxyl group, ammonolysis of the ester bond yields an amide. The decreased swelling characteristics observed following ammonia pretreatment indicate reduced polyionic character relative to water-washed $\mathrm{NaOH}$-treated materials. However, chemically combined nitrogen (via amide formation) or residual ammonia/ammonium will contribute to overall nitrogen content, and therefore may improve the value of ammonia-treated materials as a ruminant feed.

\section{Dilute Acid Hydrolysis}

When biomass is heated to high temperatures, autohydrolysis of hemicellulose and, to a lesser extent, cellulose occurs, catalyzed in part by acetic acid formed by cleavage of acetyl groups. The catalytic effect of acids on cellulose and hemicellulose hydrolysis has long been recognized, and dilute acid hydrolysis forms the basis of many pretreatment processes. Dilute acid catalysis enables prehydrolysis to be carried out at a lower temperature and thereby reduces sugar decomposition; dilute sulfuric acid catalysis improves steam explosion saccharification yields (Brownell et al. 1986).

Exposure to concentrated acid and then later to dilute acid was originally used to directly saccharify lignocellulosic materials (Sherrard and Kressman 1945). Above moderate temperatures, however, direct saccharification suffers from low yields because of sugar decomposition. Thus, exposure to dilute acid at high temperature is now being used as a pretreatment for enzymatic saccharification to improve rates and yields. Whereas older acid-based saccharification processes largely destroyed the predominantly xylan hemicellulose fraction, current processes use less severe conditions and achieve high xylan to xylose conversion yields. Xylan represents up to a third of total lignocellulose carbohydrate, so achieving high conversion yields substantially improves overall process economics (Hinman et al. 1989).

\section{Process Description}

NREL currently favors dilute acid prehydrolysis as the pretreatment process of choice for a commercial biomass-to-ethanol process (Schell et al. 1990; Schell et al. 1991). In the dilute acid process, chipped and/or milled biomass particles of nominal $1-\mathrm{mm}$ size are impregnated with approximately $1 \%(\mathrm{w} / \mathrm{w})$ sulfuric acid (liquid basis) and then incubated at $140^{\circ}-160^{\circ} \mathrm{C}$ for a period ranging from several minutes to an hour. NREL researchers have characterized the susceptibility of a variety of short rotation woody and herbaceous crops and agricultural residues to this dilute acid pretreatment process (Grohmann et al. 1985; Grohmann et al. 1986; Torget et al. 1988; Spindler et al. 1989; Torget et al. 1990a,b). High-temperature dilute sulfuric acid treatment causes hemicellulose to hydrolyze. Hemicellulose removal increases porosity and improves enzymatic digestibility; cellulose conversion yields on many dilute acid pretreated materials are greater than $90 \%$. Hemicellulose hydrolysis rates vary with temperature, but for most short rotation woody and herbaceous crop species, complete hemicellulose hydrolysis occurs in $5-10 \mathrm{~min}$ at $160^{\circ} \mathrm{C}$, or in $30-60 \mathrm{~min}$ at $140^{\circ} \mathrm{C}$. Maximum digestibility usually coincides with complete hemicellulose removal. Corn cobs are particularly easy to pretreat, becoming highly digestible after only $5 \mathrm{~min}$ of incubation at $140^{\circ} \mathrm{C}$ (Torget et al. 1990b).

There are several potential disadvantages associated with NREL's dilute acid pretreatment process. Posttreatment neutralization of residual sulfuric acid with lime creates substantial quantities of calcium sulfate (gypsum) that must be disposed of because it has little value. Also, sugar decomposition invariably reduces the maximum yields attainable upon subsequent enzymatic hydrolysis. Finally, the process suffers from extensive solids handling requirements.

Two issues that affect the overall economics of the process are digestibility and materials of construction. Although lignocellulosic digestibility is improved substantially by dilute acid pretreatment, further 
improvements in enzymatic hydrolyis rates and yields are sought to make the economics of the process more attractive. Also, inexpensive materials for construction of a large-scale high-temperature dilute acid process need to be identified.

The kinetics of dilute acid hydrolysis are reviewed before discussing steam explosion, which is also based on high-temperature prehydrolysis of biomass, often catalyzed by dilute acid. This discussion identifies the dominant factors influencing hydrolysis yields.

\section{Kinetics}

Literature and data on the kinetics of dilute acid pretreatment primarily exist for two types of processes, low solids loading $\left(5 \%-10 \%\right.$ [w/w]), high-temperature $\left(T>160^{\circ} \mathrm{C}\right)$, continuous-flow processes (Knappert et al. 1980; Knappert et al. 1981; Kwarteng 1983; Grethlein et al. 1984; Brennan et al. 1986; Converse et al. 1989); and higher solids loading (10\%-40\% [w/w]), lower temperature $\left(\mathrm{T}<160^{\circ} \mathrm{C}\right)$, batch type processes (Saeman 1945; Root 1956; Horwath et al. 1983; Cahela et al. 1983; Grohmann et al. 1985; Maloney et al. 1985; Kim and Lee 1987).

The kinetics of high-temperature wood saccharification catalyzed by dilute acid were first extensively investigated by Saeman (1945), who concluded "a study of the hydrolysis of more than twenty different woods, celluloses, and cellulose preparations at temperatures ranging from $170^{\circ}$ to $193^{\circ} \mathrm{C}$ with a fourfold change in liquid-solid ratio and a tenfold change in acid concentration, established that the hydrolysis of cellulose in dilute acid follows the laws of a first-order reaction." Moreover, in the same work Saeman showed that in solution individual monomer sugars initially decompose according to first-order kinetics; decomposition kinetics become more complex as degradation products accumulate (Root 1956; Kwarteng 1983). Consequently, Saeman modeled overall cellulose hydrolysis using consecutive first-order reactions.

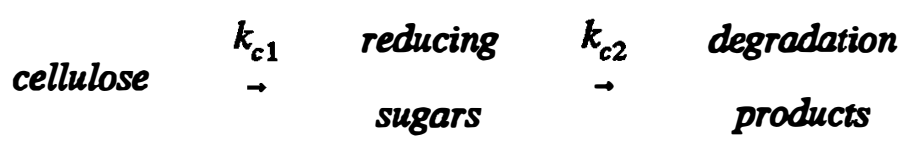

The relationship described by Equation (2) can be generalized when reactants and products are represented on an equivalent sugar monomer basis. Equation (3) shows the general case in which biomass carbohydrate species A (cellulose or xylan) hydrolyzes to B (glucose/cellobiose or xylose), which then decomposes to $\mathrm{C}$ (hydroxymethylfurfural from glucose and furfural from xylose).

$$
A \stackrel{k_{1}}{\rightarrow} B \stackrel{k_{2}}{\rightarrow} C
$$

Expressions for the net rate of formation of components $\mathrm{A}, \mathrm{B}$, and $\mathrm{C}$ can be integrated to determine the concentrations of $A$ and $B$ as a function of time and initial conditions. Equations (4) and (5) give the concentrations of A and B, respectively, for the case of batch reaction with no heat or mass transfer limitations (Seaman 1945; Grethlein 1978).

$$
C_{A}=C_{A_{0}} e^{-k_{1} t}
$$




$$
C_{B}=C_{A_{0}} \frac{k_{1}}{k_{1}-k_{2}}\left[\left(1+\frac{C_{B_{0}}}{C_{A_{0}}}\left(\frac{k_{1}-k_{2}}{k_{1}}\right)\right) e^{-k_{2} t}-e^{-k_{1} t}\right]
$$

In these equations $C_{i}$ represents the concentration of component $i$ at time $t$ and $C_{i}$ denotes the initial concentration.

Grethlein (1978) showed that the concentration of product B is maximized at time $t_{\text {opt }}$

$$
t_{\text {opt }}=\frac{1}{k_{2}(K-1)} \ln \left(\frac{K}{Q}\right)
$$

where $\mathrm{K}$ is the selectivity ratio defined by

$$
K=\frac{k_{1}}{k_{2}}
$$

and $Q$ is the lumped initialization and selectivity parameter given by

$$
Q=1+\frac{C_{B_{0}}}{C_{A_{0}}}\left(\frac{K-1}{K}\right)
$$

Substitution of Equation (6) into Equation (5) yields an expression for the maximum concentration of product B. (Note: the expression published by Grethlein [1978] is incorrect.)

$$
C_{B}\left(t_{o p t}\right)=C_{A_{o}}\left(\frac{Q^{K}}{K}\right)^{\frac{1}{K-1}}
$$

Figure 10 shows maximum yield as a function of the selectivity ratio, $\mathrm{K}$, calculated using Equation (9) assuming that initially no $B$ is present. $K$ values of 100 are necessary to achieve conversion yields of $95 \%$.

The earliest kinetic studies focused on high-temperature cellulose hydrolysis in which hemicellulose (xylan) hydrolysis occurs rapidly following first-order kinetics (Saeman 1945; Root 1956). Equations (4) and (5) are therefore also useful for describing xylan hydrolysis and decomposition at high temperatures $\left(\mathrm{T}>160^{\circ} \mathrm{C}\right)$.

Hemicellulose hydrolysis is not homogeneous at lower temperatures $\left(\mathrm{T}<160^{\circ} \mathrm{C}\right)$, however, with a portion hydrolyzing rapidly while the remainder hydrolyzes more slowly. Grohmann et al. (1985) were among the first to observe this inhomogeneity during low-temperature hydrolysis. They concluded that in the initial stages of hydrolysis both fast and slow fractions of xylose are hydrolyzed to xylose by parallel firstorder reactions. The fraction of slow-reacting xylan is estimated to be 0.20-0.32 (Grohmann et al. 1985; Maloney et al. 1985; Kim and Lee 1987). 


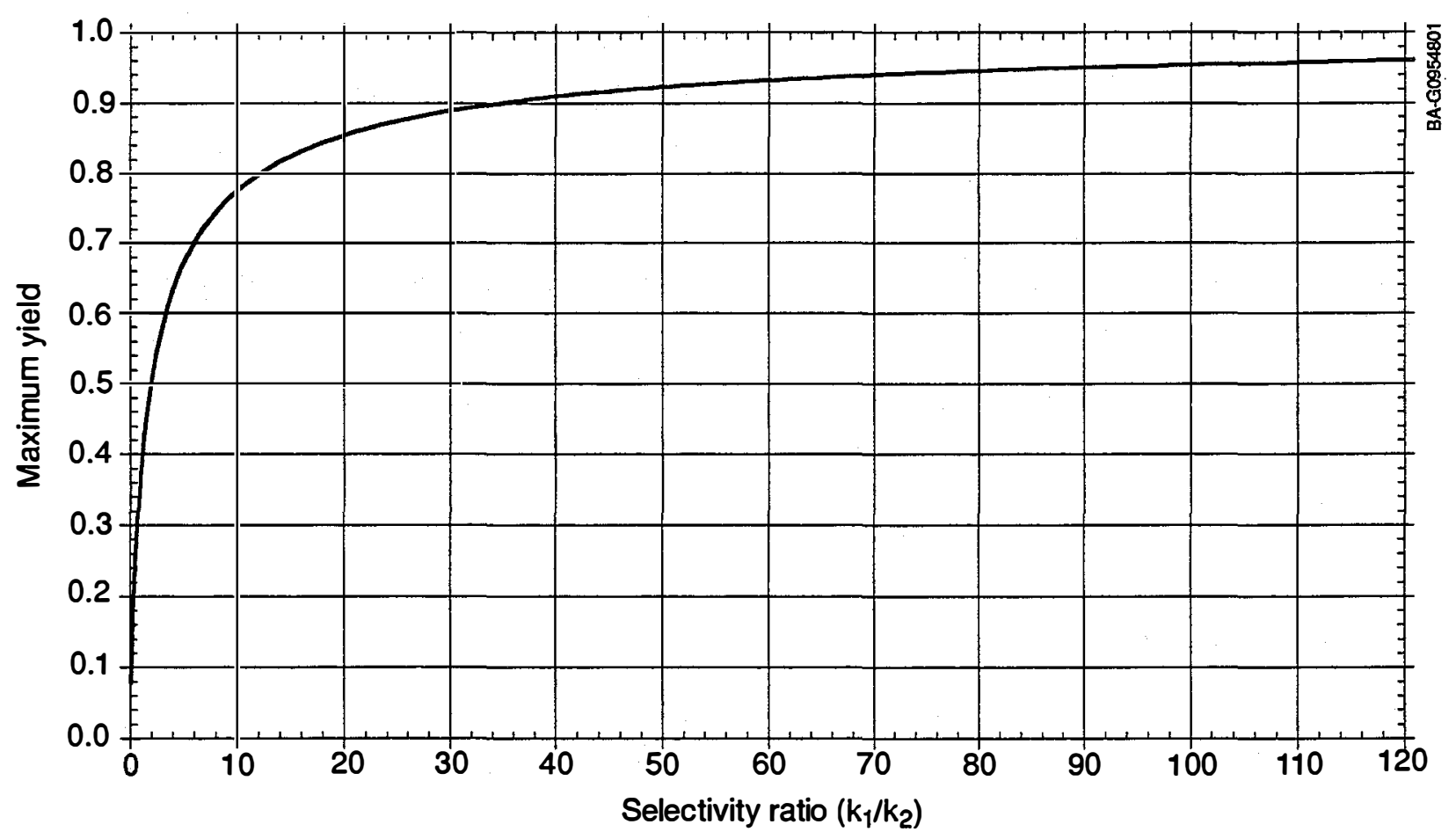

Figure 10. Maximum yield as a function of selectivity ratio for the sequential first order reaction series $A \rightarrow B \rightarrow C$. Yield is calculated by Equation (9) for the case when no $B$ is initially present $(Q=1)$.

Equation (10) depicts the reaction scheme for low-temperature hemicellulose hydrolysis.

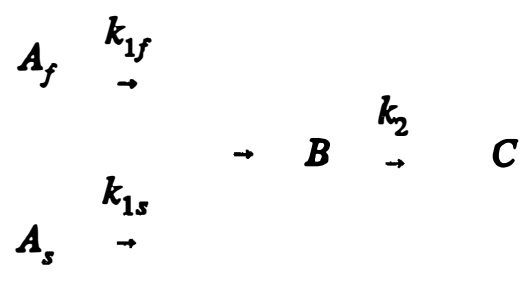

$A_{f}$ and $A_{s}$ represent the fast and slow reacting portions of xylan, respectively, and $k_{1 f}$ and $k_{1 s}$ are the corresponding rate constants. $\mathrm{A}_{0}$ represents total initial xylan (on a equivalent monomer basis). The amount of each fraction is calculated as the product of total xylan concentration and weight fraction, with $\Phi$ denoting the weight fraction of total xylan that hydrolyzes slowly.

$$
\begin{aligned}
& A_{f}=(1-\Phi) A_{0} \\
& A_{s}=\Phi A_{0}
\end{aligned}
$$

Equation (5) describes the net rate of formation of xylose from a single hemicellulose fraction, since xylose formation and degradation are both first order. Summing the contributions of xylose formed from 
fast and slow reacting hemicellulose portions gives an expression for the total concentration of xylose as a function of time. Equation (12) describes total xylose concentration when the initial xylose concentration is zero.

$$
C_{B}=C_{A_{0}}\left(\frac{k_{1 s}}{k_{2}-k_{1 s}} \Phi\left(e^{-k_{1 s} t}-e^{-k_{2} t}\right)+\frac{k_{1 f}}{k_{2}-k_{1 f}}(1-\Phi)\left(e^{-k_{1 s} t}-e^{-k_{2} t}\right)\right)
$$

It is difficult to directly compare the results of most studies of dilute acid hydrolysis kinetics reported in the literature because studies use many different substrates and different sample preparation methods (extent of grinding or drying prior to dilute acid hydrolysis, etc.). Studies also use a variety of batch and continuous reactor types, and conditions employed to initiate and quench hydrolysis vary widely. Studies account for the dependence on acid loading in different ways. Often the effect of acid concentration is correlated in terms of weight percent acid on a dry substrate basis rather than hydrogen ion molarity. Finally, studies often overlook the neutralizing ability of biomass on the effective acid concentration.

Kim and Lee (1987) review the kinetics of acid-catalyzed hydrolysis of hemicellulose and provide a useful tabulation of previously published kinetic rate constants. There is wide variation in reported rate constant values, reflecting differences in the substrate and pretreatment conditions used, the model employed, and the method by which the effective acid concentration (or weight percent) was determined. Unfortunately, only a few researchers have performed detailed kinetic studies in which both hydrolysis and decomposition rates are determined. Kim and Lee (1987) carried out the only study including both fast and slow xylan fractions and xylose decomposition.

Figure 11 shows simulations of xylan hydrolysis yield profiles (using Equation [12]) with an acid loading of $1.0 \%$ by weight and a slow reacting xylan fraction of 0.30 . Values for the individual rate constants are those obtained by Kim and Lee (1987) in experiments characterizing hydrolysis of $0.15-$ to $0.425-\mu \mathrm{m}$ screened sawdust particles of southern red oak (hardwood) at a solid to liquids ratio of 1:1.6 and a sulfuric acid loading of 1-5 wt \%. Kim and Lee (1987) corrected the effective acid concentration used in their experiments by accounting for the buffering capacity of southern red oak, which they had previously determined to be 7.5-9.0 $\mathrm{g} \mathrm{H}_{2} \mathrm{SO}_{4} / \mathrm{kg}$ biomass. This correction reduced the effective weight percent acid used in their experiments by about $0.5 \mathrm{wt} \%$. Note that although simulations are shown for temperatures from $120^{\circ} \mathrm{C}$ up to $220^{\circ} \mathrm{C}$, the simulations at temperatures of $160^{\circ} \mathrm{C}$ and above are extrapolations, since Kim and Lee (1987) only determined rate constants at temperatures from $120^{\circ} \mathrm{C}$ to $140^{\circ} \mathrm{C}$. Simulation results show that maximum xylose yield is $80 \%$, increasing slightly with increasing pretreatment temperature.

Figure 12 shows characteristic normalized profiles (simulated) for total potential xylose (xylan plus xylose), free xylose (hydrolyzed xylan), and xylose decomposition products as a function of hydrolysis time at $160^{\circ} \mathrm{C}$. Again, rate constants from Kim and Lee (1987) are used, and the simulations assume $1.0 \%$ by weight sulfuric acid and a slowly hydrolyzed xylan fraction of 0.30 . Only after free xylose has accumulated in solution does xylose degradation become significant.

Figure 13 shows selectivity ratios based on the rate constants determined by Kim and Lee (1987). The selectivity ratio for fast xylan hydrolysis relative to xylose degradation, $K_{f}=k_{1 f} / k_{2}$, increases with temperature, from a value of 42 at $120^{\circ} \mathrm{C}$ to a value of 67 at $220^{\circ} \mathrm{C}$. A smaller increase is observed in the selectivity ratio for slow xylan hydrolysis, $\mathrm{K}_{s}=\mathrm{k}_{1 \mathrm{~s}} / \mathrm{k}_{2}$, with the value rising over the same temperature 


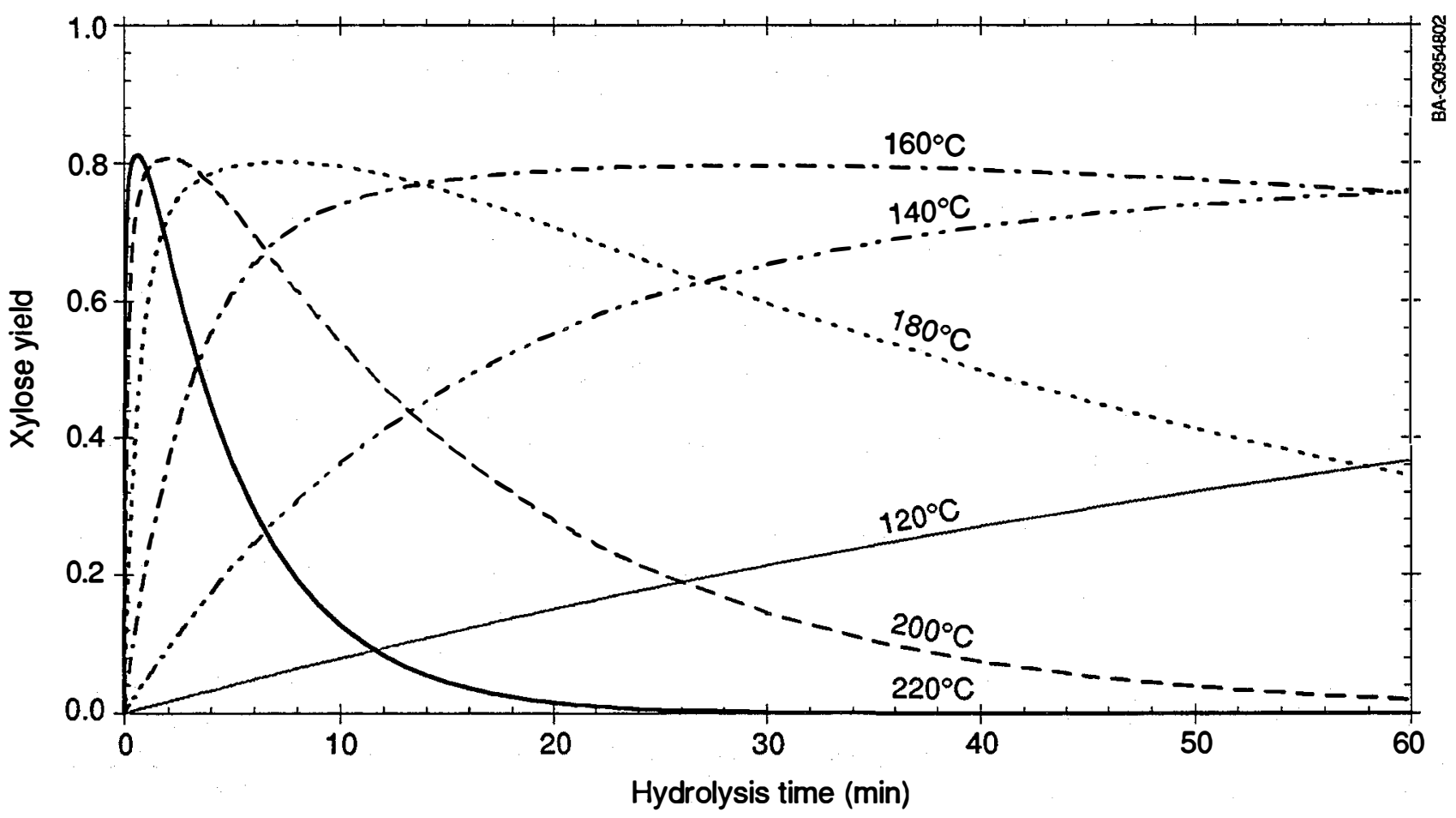

Figure 11. Xylose yield as a function of time. Yield is calculated by Equation (12) using the rate constants of Kim and Lee (1987) assuming an acid loading of $1.0 \%$ by weight and a slow reacting xylan fraction of 0.30 .

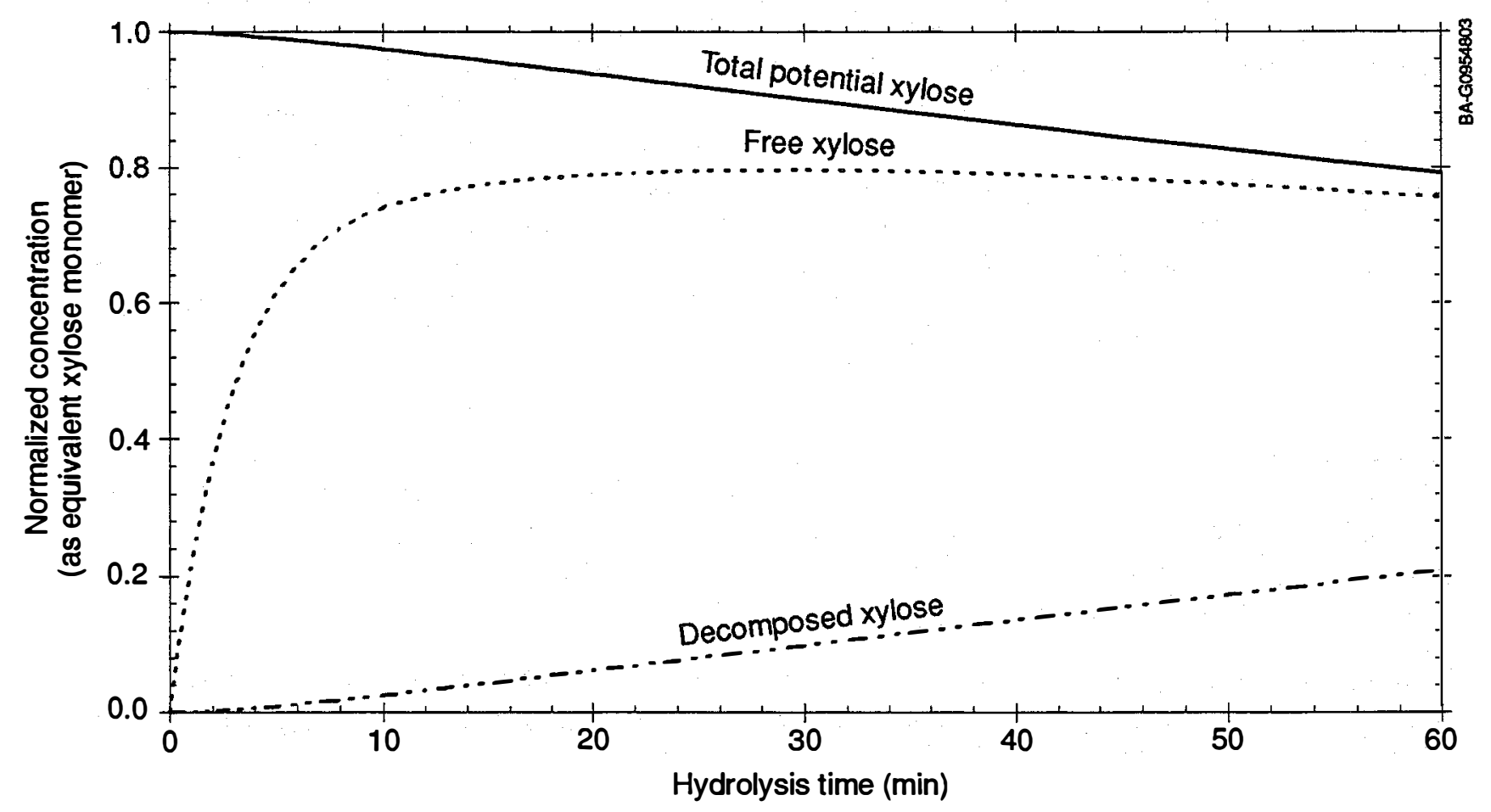

Figure 12. Total potential xylose, free xylose, and decomposed xylose as a function of hydrolysis time at $160^{\circ} \mathrm{C}$. Conditions are the same as in Figure 11. 


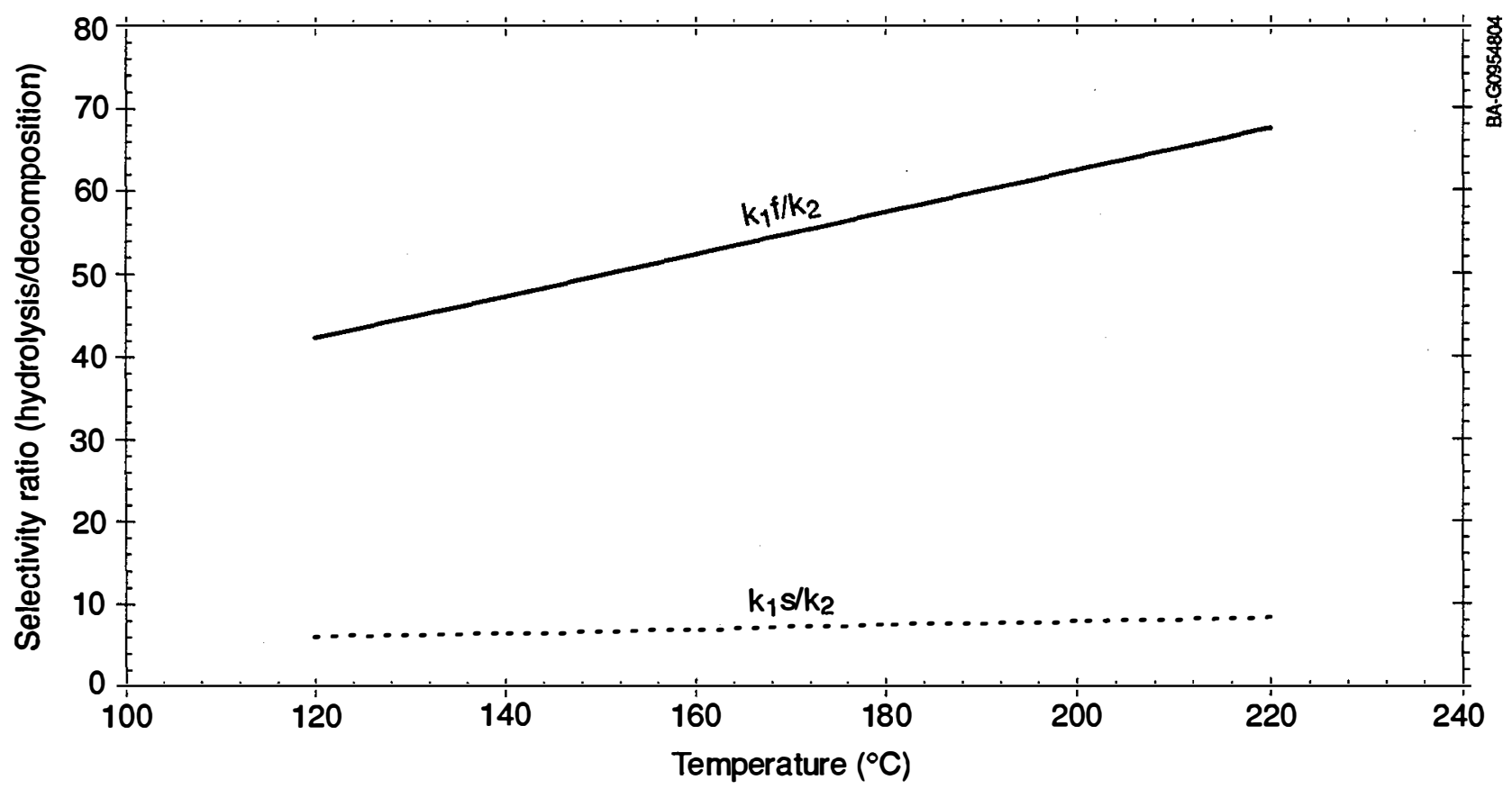

Figure 13. Selectivity ratios as a function of temperature. Individual rate constants determined from Kim and Lee (1987). Conditions are the same as in Figure 11.

range from about 6 to 8 . The temperature sensitivity of the $K_{i}$ selectivity ratios reflects a lower activation energy for xylose degradation $(112.6 \mathrm{~kJ} / \mathrm{g} \mathrm{mol}[26.9 \mathrm{kcal} / \mathrm{g} \mathrm{mol}])$ relative to fast $(120.1 \mathrm{~kJ} / \mathrm{g} \mathrm{mol}$ [28.7 kcal/g mol]) and slow $(118.0 \mathrm{~kJ} / \mathrm{g} \mathrm{mol}$ [28.2 kcal/g mol]) xylan hydrolysis.

It is easy to be deluded about the robustness of kinetic data. Experimentally determined rate constants generally can only be used to predict hydrolysis profiles from similar experiments. Unfortunately, almost every research group carries out somewhat different hydrolysis experiments, and variations in the kinetic constant values determined by different researchers are the rule. This is easily illustrated by examining a simulation based on an alternative set of kinetic rate constants.

Figure 14 shows simulated xylose yield profiles (using an acid loading of $1.0 \%$ by weight and a slow reacting xylan fraction of 0.30 ), based on kinetic rate constants measured by Maloney et al. (1985) (xylan fast and slow hydrolysis) and Root (1956) (xylose decomposition). Again, profiles are shown for pretreatment temperatures ranging from $120^{\circ}$ to $220^{\circ} \mathrm{C}$. Maximum xylose yields are greater than $95 \%$, in contrast to the $80 \%$ value observed using kinetic constants from Kim and Lee (1987). Higher maximum yields are the result of higher selectivity ratios. As Figure 15 shows, the selectivity ratio based on the fast-reacting xylan fraction falls from 1050 at $120^{\circ} \mathrm{C}$ to 700 at $220^{\circ} \mathrm{C}$, but for the slow reacting fraction rises from about 50 to 250 over the same temperature range. Again, the temperature dependence in selectivity values reflects differences in apparent activation energies, which are $126.6 \mathrm{~kJ} / \mathrm{g} \mathrm{mol}$ $(30.3 \mathrm{kcal} / \mathrm{g} \mathrm{mol})$ and $156.5 \mathrm{~kJ} / \mathrm{g} \mathrm{mol}(37.4 \mathrm{kcal} / \mathrm{g} \mathrm{mol})$ for fast and slow xylan fractions, respectively, and $133.8 \mathrm{~kJ} / \mathrm{g} \mathrm{mol}(32.0 \mathrm{kcal} / \mathrm{g} \mathrm{mol})$ for the xylose decomposition reaction. These xylan hydrolysis kinetics are based on disparate kinetic constants, however. 


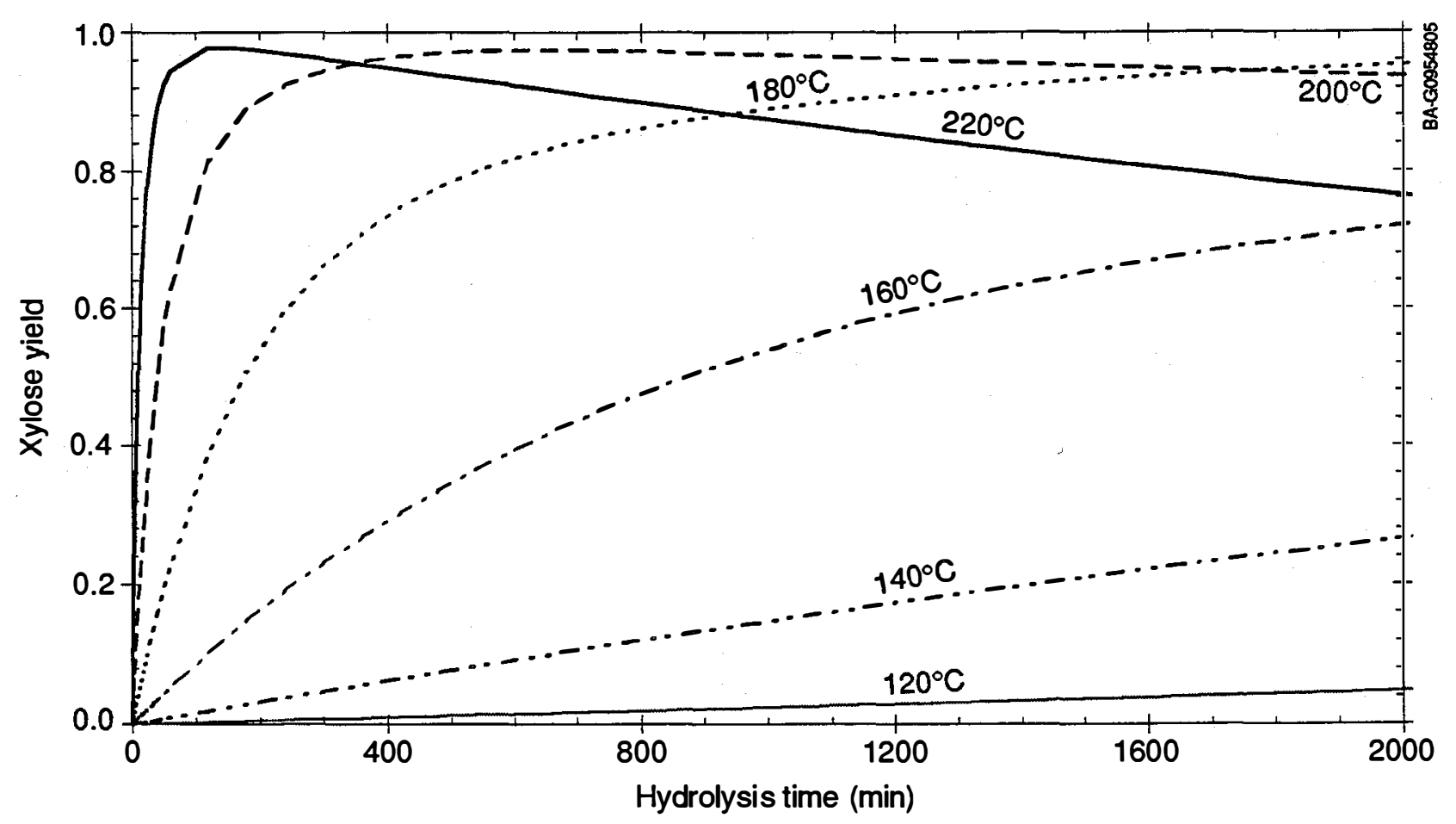

Figure 14. Xylose yield as a function of time. Yield is calculated by Equation (12) using the xylan hydrolysis rate constants of Maloney et al. (1985) and a xylose degradation rate constant from Root (1956). Calculations assume an acid loading of $1.0 \%$ by weight and a slowreacting xylan fraction of 0.30 .

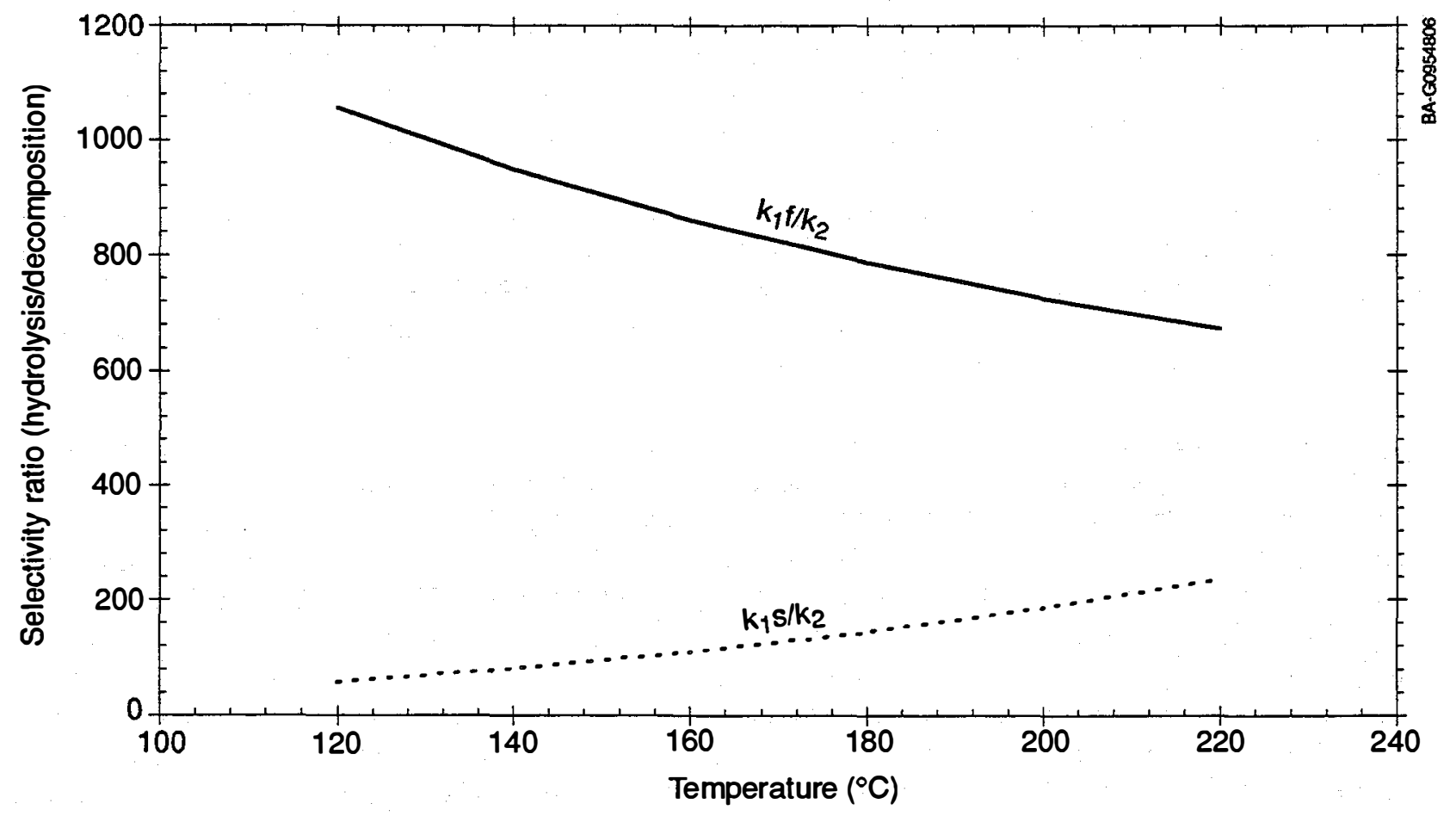

Figure 15. Selectivity ratios as a function of temperature. Individual rate constants determined from Maloney et al. (1985) and Root (1956). Conditions are the same as in Figure 14. 
Maloney et al. (1985) examined the hydrolysis of 0.01-in.-thick wafers of wet white birch using temperatures of $100^{\circ}-170^{\circ} \mathrm{C}$ and sulfuric acid concentrations of $0.04-0.18 \mathrm{M}$. Root (1956), on the other hand, studied the decomposition of pure xylose at temperatures of $160^{\circ}-280^{\circ} \mathrm{C}$ and acid concentrations of $0.003-$ $0.4 \mathrm{M}$. This may also partially explain the significant differences that exist between the predicted xylose yield and selectivity profiles using the kinetic constants of Maloney et al. (1985) and Root (1956) (Figures 14 and 15) and those generated using the rate constants of Kim and Lee (1987) (Figures 11 and 13).

The dependence on acid loading is typically incorporated into an Arrhenius-type relationship as shown in Equation (13).

$$
k_{i}=k_{i_{0}} C_{H^{*}}^{n} e^{\frac{-E_{l}}{R T}}
$$

In this equation, $k_{i}$ represents the kinetic rate constant for reaction $i, k_{i o}$ the preexponential factor, $C_{H}$, the effective acid concentration, $n$ the exponent on acid loading, $E_{i}$ the activation energy, $R$ the universal gas constant, and $\mathrm{T}$ the temperature. Biomass species differ significantly in their ability to neutralize acids. Some authors, however, have not considered acid concentration dependence (Grohmann et al. 1985), while others have neglected to correct acid concentration (Kwarteng 1983; Cahela et al. 1983). Kim and Lee (1987) estimated the amount of acid neutralized from results of a previous neutralization study. Maloney et al. (1985) performed a more detailed analysis.

Maloney et al. (1985) carried out an analysis of the effect of acid concentration on hydrolysis rates that considered both the neutralization capacity of biomass and the reduced dissociation of sulfuric acid at high temperature. It was assumed that only $1 \mathrm{~mol}$ of hydrogen ions was obtained from each mol of sulfuric acid, since at the high temperatures $\left(100^{\circ}-170^{\circ} \mathrm{C}\right)$ used in their hydrolysis experiments more than $97 \%$ of the sulfate existed as bisulfate. The neutralizing capacity of the biomass was calculated assuming that $1 \mathrm{~mol}$ of hydrogen ions was neutralized by each mol of inorganic cations that was dissolved during hydrolysis. Atomic absorption spectroscopy was used to determine the inorganic cation content $(\mathrm{Ca}, \mathrm{Mg}$, and $\mathrm{Mn}$ ) of unreacted and hydrolyzed samples, and thereby quantify the extent of cation dissolution during hydrolysis. Correcting for both factors yielded a neutralization capacity of $3.5 \mathrm{~g}$ sulfuric acid/kg biomass (white birch). The exponents on acid concentration determined using corrected acid concentration values were very close to 1 , being $0.93 \pm 0.05$ and $1.02 \pm 0.16$ for the fast and slow reacting xylan fractions, respectively. This indicates that dependence on effective acid concentration is roughly linear. Although exponents on acid concentration reported in the literature range from about 0.5 to 1.5 , this is probably because most researchers have not adequately considered high-temperature acid dissociation and/or the neutralizing capacity of biomass.

\section{Explosive Decompression-based Methods}

\section{Steam Explosion}

Steam explosion is a variation of the high-temperature dilute acid hydrolysis technique in which chipped biomass is treated with saturated steam in a pressure vessel, which is then flashed, causing explosive disruption of the biomass by liberated steam. Steam explosion pretreatments are typically carried out using saturated steam at temperatures of $160^{\circ}-260^{\circ} \mathrm{C}$, which corresponds to pressures of $0.69-4.83 \mathrm{MPa}$ (100-700 psia) (Perry et al. 1984) and residence times of tens of seconds to several minutes. Steam explosion is today the most commercialized of all of the pretreatment techniques, and numerous reviews of steam explosion are available (Brownell and Saddler 1984; Brownell et al. 1986; Clark and Mackie 1987). In general, both the rate and extent of enzymatic hydrolysis achievable following steam explosion pretreatment increase with increasing duration of treatment. This, however, refers only to the washed 
solids remaining after pretreatment; because of the formation of degradation products that are inhibitory to microbial growth, steam-exploded biomass must be washed prior to enzymatic hydrolysis and subsequent fermentation. The extent and rate of hydrolysis of the solids remaining following pretreatment and washing increase with the severity of treatment. However, overall saccharification yields fall because washing removes soluble sugars, such as those from hemicellulose hydrolysis.

Research on steam explosion has demonstrated that extensive hemicellulose degradation and lignin modification can take place, particularly at high steam temperatures or long reaction times. Schultz et al. (1983), for example, steam exploded unscreened 1- to 150-mm-long mixed southern hardwood chips obtained from a wood yard. Steam temperature was varied from $167^{\circ} \mathrm{C}$ to $235^{\circ} \mathrm{C}$ with residence times from 0.5 to $2 \mathrm{~min}$. At the higher temperature, roughly $67 \%$ of the hemicelluloses were degraded, and some of the degradation products condensed with lignin. It was concluded that some depolymerization of lignin was occuring, since much of the lignin could be extracted using aqueous $\mathrm{NaOH}$.

A detailed study of the effect of process parameters on the efficacy of the steam explosion process was carried out by Brownell and Saddler (1984) using 3.2-mm aspen chips and steam temperatures up to $250^{\circ} \mathrm{C}$. They found that some destructive pyrolysis occured in addition to carbohydrate hydrolysis and degradation, particularly at higher reaction temperatures and longer reaction times. Brownell and Saddler (1984) observed full solubilization of the pentosan fraction in $1 \mathrm{~min}$ using $250^{\circ} \mathrm{C}$ steam, and the pentosan fraction was more than $60 \%$ destroyed after $2 \mathrm{~min}$ of treatment. An important finding was that impregnation with $0.2 \% \mathrm{H}_{2} \mathrm{SO}_{4}$ improved the selectivity of the process to favor hydrolysis over pyrolysis and degradation. In addition to permitting more complete hemicellulose solubilization and reducing degradation, washed material performed better as a substrate for enzymatic hydrolysis when an acid catalyst was used. These results were confirmed in a later study, which showed that the use of an acid catalyst permitted the use of lower steam temperatures (Brownell et al. 1986).

Brownell and Saddler (1984) found that heating the moisture content of biomass dominated the steam consumption requirements, and recommended using dried or partially dried wood to reduce steam costs. Furthermore, based on their results at $250^{\circ} \mathrm{C}$, they recommended either decreasing the chip size to less than $6 \mathrm{~mm}$ or increasing the incubation time and reducing steam temperature to avoid the problem of heat transfer heterogeneity, which causes overcooking (degradation) to occur at the outsides of the chips or undercooking to occur at the center.

In a later paper, Brownell et al. (1986) report on temperature studies that show the importance of steam (heat) penetration along the fiber axis. Optimum treatment times increase with increasing moisture content. Convective heat transfer occurs in air-dried chips, even large ones, if steam can enter the end grain and uniformly penetrate into the biomass by moving through open vessels. In contrast, for wet or green chips in which pores and vessels are filled with water (or steam condensate), or when vessels are blocked by tyloses, rapid convection cannot occur and heat transfer occurs by conduction alone.

There are two potential mechanisms of action of steam explosion pretreatment. First, rapid solubilization of hemicellulose opens up the pore structure of the biomass, similar to what occurs during dilute acid hydrolyis. This has been amply demonstrated to occur following high-temperature and acid-catalyzed treatments. Second, explosive decompression exerts a mechanical shear on the biomass, which may increase the specific surface area of the material by defibrating individual cellulose microfibrils or by otherwise expanding the lignocellulose matrix. Although there is little doubt about the importance of the first mechanism, controversy exists regarding the importance of explosive decompression. The study by Brownell et al. (1986), for example, concluded that explosion was unneccessary, since hydrolysis yields were similar using pressure drops ranging from $0.34 \mathrm{MPa}$ (50 psia) to $3.24 \mathrm{MPa}$ (470 psia) to "explode" the material. 
Mackie et al. (1985) compared the effect of impregnation with either $\mathrm{SO}_{2}$ or $\mathrm{H}_{2} \mathrm{SO}_{4}$ on the performance of steam explosion pretreatment of aspen wood. These acid catalysts improved the yield of pentose sugars to a similar extent to each other. Lignin was easier to extract from water-washed pretreated material when $\mathrm{SO}_{2}$ was used, however. Roughly $50 \%$ of input sulfur bound to substrate, and this was attributed to the formation of lignosulfonates. It was unclear whether the greater lignin solubility resulted from the formation of lignosulfonates or was caused by a lower molecular weight lignin fraction being created by $\mathrm{SO}_{2}$ treatment.

Clark and Mackie (1987) showed that $\mathrm{SO}_{2}$ impregnation prior to steam explosion could also be used to increase the susceptibility of softwood to enzymatic hydrolysis. Screened wood particles (16- to 22-mm), either green or containing $43 \%$ water (dry basis), were impregnated with $\mathrm{SO}_{2}$ for $10-50$ min prior to steam explosion. Steam explosion experiments were conducted using steam temperatures of $180^{\circ}-250^{\circ} \mathrm{C}, \mathrm{SO}_{2}$ loadings of $0.55-11.8 \%(\mathrm{w} / \mathrm{w})$, and residence times of $0.5-18 \mathrm{~min}$. Digestibilities of greater than $85 \%$ were reported for several of the conditions examined. However, since digestibility studies were performed only on the water-insoluble fraction that remained after washing, such high values for digestibility are somewhat misleading. Water-insoluble mass yields following steam explosion and washing were less than $60 \%$ in all cases, indicating that significant solubilization and/or destruction of hemicellulose components occurred. Clark and Mackie's contour plot results show that similar overall (total) yields can be obtained for a range of temperature-time combinations, either high-temperature, short-residence-time, or lower temperature, longer residence time. Thus, time and temperature are inversely related, although in a manner dependent on the $\mathrm{SO}_{2}$ level; the effect of $\mathrm{SO}_{2}$ falls off above a loading of $3 \%(\mathrm{w} / \mathrm{w})$, but is pronounced at loadings between $0.5 \%$ and $3 \%(w / w)$.

As shown in Figure 16, digestibility correlated strongly with carbohydrate content of the water-insoluble fraction, with a very sharp increase $(0 \%-100 \%)$ in digestibility occurring as the carbohydrate content decreased from $67 \%$ to $50 \%$. These results clearly show that the presence of lignin does not by itself cause poor enzymatic hydrolysis yields. Indeed, Figure 16 illustrates that significant improvements in digestibility result from partial hemicellulose removal. The maximum total sugar yields (soluble plus insoluble fractions) of $57 \%-60 \%$ represent only about $80 \%-84 \%$ of the sugar theoretically available in the softwood. Since between $5 \%-8 \%$ of the potential sugar remains undigestible in the insoluble fraction, losses of about $10 \%-12 \%$ are due to actual degradation, mostly of the hemicellulose fraction. Unfortunately, their data also indicate that in many instances more sugar is solubilized by steam explosion than is subsequently obtained by enzymatic hydrolysis of the water-insoluble fraction.

Using the solute exclusion technique, Wong et al. (1988) showed that increased porosity (accessible surface area) is the primary mechanism by which $\mathrm{SO}_{2}$ impregnation-based steam explosion increases softwood digestibility. They recognized, however, that lignin redistribution during or following steam explosion pretreatment might also be increasing digestibility. Their experimental results showed the importance of the post-treatment wash. Reduced digestibility was observed when steam-exploded material was washed with a caustic rather than water, presumably because of partial pore collapse. Reduced digestibility because of partial pore collapse is also observed after drying, or after acid washing of alkali treated materials, as discussed previously.

Galbe and Zacchi (1986) investigated the effect of $\mathrm{Na}_{2} \mathrm{SO}_{3}$ and $\mathrm{H}_{2} \mathrm{SO}_{4}$ impregnation on the steam explosion of air-dried sallow particles $1.0-3.15 \mathrm{~mm}$ in size. Steam temperatures of $180^{\circ}-235^{\circ} \mathrm{C}$ and residence times of 2-20 min were investigated. Overall, their results corroborate the results of others, with significant losses occuring upon washing the steam-exploded material. Slightly higher xylose yields were observed with $\mathrm{Na}_{2} \mathrm{SO}_{3}$, with xylose yield increasing from $20 \%$ to $30 \%$. 


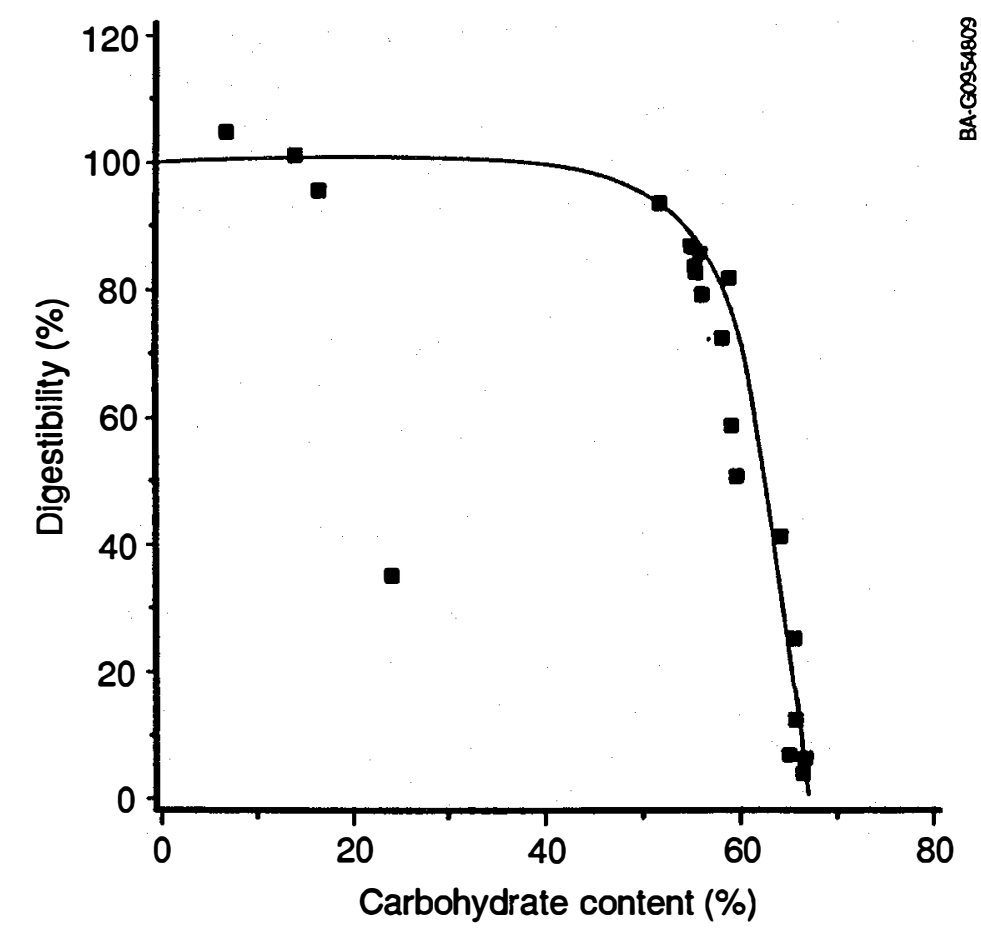

Figure 16. Digestibility of water-insoluble fiber as a function of carbohydrate content. (Reprinted with permission from Clark and Mackie 1987, J. Wood Chem. Tech. 7(3): 373-403, courtesy of Marcel Dekker, Inc.)

\section{Ammonia Explosion}

Ammonia explosion, or ammonia fiber explosion (AFEX) as it is more popularly known, is a process developed by B. Dale in the early 1980s at Colorado State University (Dale and Moreira 1982; Dale et al. 1985), and currently being researched by M. Holtzapple, B. Dale, and others at Texas A\&M University (Holtzapple et al. 1990a-c).

The AFEX method consists of treating a lignocellulosic material with volatile liquid ammonia under pressure, followed by pressure release to evaporate the ammonia and explode the material. In an AFEX pretreatment, ground (1-2 mm characteristic dimension) prewetted lignocellulosic material at a moisture content of $0.15-0.30 \mathrm{~kg}$ water $/ \mathrm{kg}$ dry biomass is first placed in a pressure vessel with liquid ammonia at a loading of about $1 \mathrm{~kg}$ ammonia/kg dry biomass. The vapor pressure of ammonia is high $\left(\mathrm{P}_{\text {vap }}=\right.$ 1.06 MPa [154 psia] at $300 \mathrm{~K}$ ), and the pressure becomes quite high in the closed pressure vessel; the vessel pressure reaches about $1.24 \mathrm{MPa}$ (180 psia) when the process is carried out at ambient temperature (Dale and Moreira 1982). The mixture is then incubated at the reaction pressure for sufficient time, typically on the order of tens of minutes to an hour, to enable ammonia to penetrate the lignocellulosic matrix. Finally, a valve is opened to flash the reaction mixture to a lower, although possibly nonambient, pressure. Pretreated samples are left out overnight to vaporize residual ammonia.

AFEX pretreatment has been demonstrated to markedly improve the saccharification rates of numerous herbaceous crops and grasses. Materials successfully pretreated using the AFEX process include alfalfa, com stover, rice stover, wheat straw, barley straw, bermuda grass, bagasse, and kenaf core 
(Dale et al. 1985; Holtzapple et al. 1990a,b). Following AFEX pretreatment, overall hydrolysis yields on these materials are $80 \%$ to $90 \%$ of theoretical (Dale et al. 1985); overall hydrolysis yield refers to the combined cellulose and hemicellulose conversion yield based on total reducing sugars in the hydrolyzate (measured by the dinitrosalicylic acid method [Miller 1959]). AFEX pretreatment has not been successfully applied to traditionally more resistant materials such as hardwoods and softwoods. When aspen chips were subjected to AFEX pretreatment, hydrolysis yields remained below 50\% (Dale and Holtzapple 1989). Attempts to pretreat newspaper using AFEX have been even less successful, achieving a maximum $40 \%$ hydrolysis yield (Holtzapple et al. 1990a).

The mechanism of action of AFEX pretreatment is apparently dual. First, the reactivity of cellulose is increased by exposure to liquid ammonia. As discussed in the previous section on swelling treatments, liquid ammonia causes swelling and may also cause partial decrystallization of crystalline cellulose. Explosive decompression following incubation in high pressure $5.62 \mathrm{MPa}(815 \mathrm{psia})$ carbon dioxide resulted in hydrolysis yields of only $75 \%$ of theoretical, whereas yields of AFEX-treated materials approached $90 \%$. Dale and Moreira (1982) hypothesize that the penetration of the liquid ammonia into the lignocellulose matrix is facilitated by the tenfold lower viscosity and surface tension of liquid ammonia relative to liquid water. Second, the accessible surface area of the biomass material increases following AFEX treatment, probably because of increased porosity caused by a combination of hemicellulose hydrolysis and the extremely rapid vaporization of liquid ammonia when the reactor is flashed. Basecatalyzed hemicellulose hydrolysis is likely, since liquid ammonia forms ammonium hydroxide in the presence of water. The increase in surface area caused by rapid vaporization of ammonia is analogous to the explosive decompression phenomenon that occurs in steam explosion pretreatment processes. When ammonia that has penetrated into the lignocellulose matrix during the high-pressure AFEX incubation period is suddenly flashed, there is a rapid expansion within lignocellulose matrix, which significantly increases the specific surface area of the biomass. Electron micrographs of untreated and AFEX-treated alfalfa qualitatively demonstrate that specific surface area increases following AFEX treatment (Dale and Moreira 1982). This is supported by the fact that the density of alfalfa falls from $290 \mathrm{~kg} / \mathrm{m}^{3}$ to $180 \mathrm{~kg} / \mathrm{m}^{3}$ following AFEX treatment, and the water holding capacity of the treated material increases by $50 \%$ (Dale and Moreira 1982).

The first experiments with AFEX pretreatment were performed at ambient temperature on alfalfa, rice straw, and wheat straw (Dale and Moreira 1982). They observed that upon flashing, the temperature in the AFEX pressure/reaction vessel rapidly fell to about $-30^{\circ} \mathrm{C}$. This freezing of the biomass was believed to be important and, reflecting this, the acronym AFEX originally stood for ammonia freeze explosion rather than ammonia fiber explosion. More recent experiments have demonstrated increased efficacy of AFEX pretreatment at higher than ambient temperatures (Holtzapple et al. 1990a,b), and freezing is no longer believed to play an important role in the process (Holtzapple 1990c). More recent experiments also demonstrate that AFEX treatment remains effective even when blowdown pressures are increased from atmospheric to around 0.30 to $0.46 \mathrm{MPa}$ (44 to $66 \mathrm{psia}$ ) (Holtzapple et al. 1990a,b). This has important implications regarding the cost of AFEX treatment, since compression costs represent a major fraction of AFEX process operating costs. Using bagasse, the effect of particle size on the efficacy of AFEX pretreatment was examined. It was determined that the AFEX pretreatment did not require very fine particle sizes, but that hydrolysis yields could be further improved by fine grinding of particles following AFEX treatment. Fine grinding of still-wet ammoniated material is reported by Holtzapple (1990b) to be much more energy efficient than fine grinding of air-dried materials prior to pretreatment.

The two most significant apparent advantages of the AFEX process relative to more conventional dilute acid pretreatment processes are its high yield and the fact that no post-treatment neutralization of $\mathrm{pH}$ is required. A major drawback of sulfuric-acid-based pretreatment processes, the need for post-treatment neutralization, is circumvented with the AFEX process. 
Another advantage is that no inhibitory degradation products (or very few) are formed in the AFEX process because of the relatively low temperatures used. This results in nearly theoretical sugar and carbohydrate yields following AFEX treament, in contrast with most competing high-temperature pretreatments (e.g., steam explosion and dilute acid hydrolysis). Also, in contrast to steam-exploded biomass, which usually must be washed to remove inhibitory degradation products, AFEX-treated biomass requires no post-treatment washing. Many AFEX-treated materials have been directly fermented to ethanol following air drying and enzymatic hydrolysis (Dale et al. 1985; Ripley 1990).

An additional potential advantage of AFEX treatment is that $0.5 \%$ to $1.5 \%$ by weight ammonia remains in air-dried AFEX-treated biomass (Dale et al. 1985). It is anticipated that nitrogen source requirements for fermentation will be reduced by the presence of this residual ammonia. Dale et al. (1985) achieved ethanol yields of $41 \%$ of theoretical on fermentation of unsupplemented AFEX-treated wheat straw after enzymatic hydrolysis for $24 \mathrm{~h}$ and concluded that residual ammonia effectively serves as a nitrogen source for yeast growth.

The major disadvantage of the AFEX process appears to be its limited efficacy on high-lignin-content materials. Results of a study on AFEX pretreament of bermuda grass, bagasse, and newspaper indicate decreasing AFEX effectiveness with increasing lignin content. AFEX treatment resulted in hydrolysis yields of over $90 \%$ of theoretical for both Bermuda grass ( $-5 \%$ lignin) and bagasse ( $-20 \%$ lignin), whereas the hydrolysis yield on AFEX-treated newspaper ( $-30 \%$ lignin) was only about $40 \%$ (Holtzapple et al. 1990a). As noted above, hydrolysis yields on aspen wood are also low.

\section{Carbon Dioxide Explosion}

Dale and Moreira (1982) briefly examined the potential of using $\mathrm{CO}_{2}$ explosion rather than ammonia- or steam-based explosion to pretreat alfalfa. Alfalfa was incubated (for an unspecified length of time at presumably ambient temperature) at a $\mathrm{CO}_{2}$ loading of $4 \mathrm{~kg} \mathrm{CO}_{2} / \mathrm{kg}$ fiber corresponding to a pressure of $5.62 \mathrm{MPa}$ (815 psia). Following incubation, the pressure was rapidly released as in the conventional steam explosion process. Seventy-five percent of theoretical glucose was released during a 24-h enzymatic hydrolysis of the exploded material. Since yields were higher following AFEX treatment at markedly lower pressures (see previous section), further experiments with $\mathrm{CO}_{2}$ were not performed.

Puri and Mamers (1983) investigated incubating biomass with steam and high-pressure $\mathrm{CO}_{2}$, and then subjecting the material to explosive decompression. Substrates examined were air-dried wheat straw hammer milled to pass through a 1-mm screen, bagasse (used as received), and green eucalyptus chips screened to pass through a $25-\mathrm{mm}$ mesh. Following direct steam injection to bring the vessel temperature up to $200^{\circ} \mathrm{C}$, the vessel was further pressurized to $3.45-13.8 \mathrm{MPa}(500-2000 \mathrm{psia}) . \mathrm{CO}_{2}$ was added to pressurize the vessel up to pressures of $4.8 \mathrm{MPa}$ (700 psia); injection of $\mathrm{N}_{2}$ was used to further increase the pressure when required. It was hypothesized that in the presence of steam (or wet biomass), $\mathrm{CO}_{2}$ would form carbonic acid that would stimulate or increase the initial "auto" hydrolysis rate. Some improvement in the extent of enzymatic hydrolysis was observed with increasing pressure at low solids loadings, with yields (expressed as percent loss of organic matter on an ash-free, oven-dry basis) increasing from about $60 \%$ to $75 \%$. However, no effect of pressure was seen at higher solids loadings, even though hydrolysis yields remained similar. No experiments were performed to test Puri and Mamers' hypothesis that additional water helped the process. Their apparatus included an exit nozzle that reportedly promoted defibration of expelled material, but no data supporting these claims were provided. 


\section{Alternative Pretreatments}

\section{Chemical-based Pulping Processes}

There are a variety of pulping techniques including sulphate, sulfite, and organosolv pulping; gases such as ozone and oxygen are also being considered for use in pulping operations. However, pulping processes generally suffer from excessive chemical recovery requirements and low yields. In addition, large capital investments are required to install the integrated chemical recovery systems necessary in most chemicalintensive pulping operations. Conventionally, pulping processes are used for producing high-quality paper pulp, or in situations in which other high-value products can be made from byproduct streams, such as furfural and/or other chemicals from xylose or adhesive resins from lignin. The potential of using pulping processes to economically pretreat lignocellulosics prior to fuel ethanol production is unclear.

Chum et al. (1985) compared the economics of organosolv- and steam-explosion-based pretreatment in the context of ethanol fuel production from lignocellulosics and concluded that organosolv is potentially competitive with steam explosion. The competitiveness of organosolv pretreatment depended on the value assumed for the byproduct lignin stream. It was recommended that organosolv processes with reduced chemical (solvents) requirements be developed to improve the economics of organosolv pretreatment.

Although there is a wealth of information on pulping techniques, a comprehensive analysis of the use of pulping in the context of biomass to ethanol production will not be attempted here. Pulping pretreatments for renewable fuels production are not expected to be economical until high end uses are developed for byproduct lignin; lignin is burned in NREL's most recent biomass-to-ethanol plant design (Schell et al. 1990). Nonetheless, there is potential to develop improved pretreatments by modifying conventional and novel pulping methods. A review of pulping methods in the context of a lignocellulosic pretreatment for fuel ethanol production is therefore warranted.

\section{Supercritical Fluid Extraction}

An overview of supercritical fluid (SCF) treatments for the extraction of chemicals from lignocellulosics is provided by Kiran (1987). Many SCF extraction/liquefaction schemes to extract lignins, resins, and waxy materials from lignocellulosics employ solvents that are liquids at room temperature and pressure. For example, McDonald et al. (1983) treated western red cedar with SCF acetone or methanol at $260^{\circ}$ $360^{\circ} \mathrm{C}$ and $10-28 \mathrm{MPa}(1450-4050 \mathrm{psia})$, achieving extraction yields of up to $74 \%$ by weight. The composition of extracted components was different than expected, however, leading the authors to speculate that degradation was taking place. Lignin extraction with supercritical fluids has also been investigated using t-butanol (Reyes et al. 1989), methylamine (Li and Kiran 1989), and binary mixtures of methylamine-water (Beer and Peter 1985) and methylamine-nitrous oxide (Li and Kiran 1989).

Using fluids that are gases at ambient temperature and pressure for SCF pretreatment is potentially advantageous because gases are often easier to recover for reuse than liquids. Gases that have been investigated for use in SCF pretreatments include ammonia, carbon dioxide, ethylene, nitrous oxide, propane, and sulfur dioxide. The nonflammable, noncorrosive, nontoxic, and inexpensive nature of $\mathrm{CO}_{2}$ makes SCF extraction using $\mathrm{CO}_{2}$ particularly attractive.

Ritter and Campbell (1986) explored the potential of using SCF extraction with $\mathrm{CO}_{2}$ as a lignocellulosic pretreatment. SCF extraction with $\mathrm{CO}_{2}\left(\mathrm{P}_{\text {crit }}=7.39 \mathrm{MPa}[1072 \mathrm{psia}] ; \mathrm{T}_{\text {crit }}=31.3^{\circ} \mathrm{C}\right)$ was used to extract and separate resin acids, fatty acids, and volatile terpenes from softwood pulp chips. Air-dried or watersaturated samples of southern pine stumpwood and ponderosa pine $(0.42-0.85 \mathrm{~mm})$ were continuously extracted for $30 \mathrm{~min}$ at temperatures of $40^{\circ}$ or $100^{\circ} \mathrm{C}$ and at pressures of $10 \mathrm{MPa}$ or $28 \mathrm{MPa}(1450$ or 4060 psia, respectively). Following extraction, vessel pressure was reduced to atmospheric within $10 \mathrm{~s}$. 
Yields of only $15 \%$ to $30 \%$ relative to ether extraction were achieved, and microscopic examination of treated material samples indicated very little opening up or defibration of wood structure. Some micrographs of treated samples showed burst bubbles of dried resins on fiber surfaces. It was hypothesized that resinous components, softened by extraction, flowed through fiber cell lumens and exited to fiber surfaces through pits. $\mathrm{CO}_{2}$ dissolved in these resinous materials rapidly volatilized on pressure reduction, leaving the appearance of burst bubbles at fiber surfaces. Because of low yields, the authors concluded that supercritical $\mathrm{CO}_{2}$ extraction is not an effective pretreatment for wood.

Shah et al. (1990) studied the potential of using monoethanolamine (MEA) and supercritical $\mathrm{CO}_{2}-\mathrm{SO}_{2}$ as pretreatment reagents for aspen wood chips. MEA pretreatment consisted of the following steps: (1) Incubating wood chips with $5 \%$ to $50 \%$ (v/v) MEA for $24 \mathrm{~h}$ and then filtering to remove free MEA solution; (2) reacting wet chips at a liquid to solids ratio of 2.5 , at $186^{\circ} \mathrm{C}$ for $3 \mathrm{~h}$ under $1.48 \mathrm{MPa}$ (215 psia) nitrogen; (3) extracting lignin by soaking reacted wood chips in $2 \%$ aqueous $\mathrm{NaOH}$ for $24 \mathrm{~h}$; and (4) washing extracted wood chips with water until the filtrate became colorless. Supercritical $\mathrm{CO}_{2}-\mathrm{SO}_{2}$ pretreatment consisted of the following steps: (1) Presoaking wood chips in 2\% $\mathrm{NaOH}$ for $24 \mathrm{~h}$ followed by filtration to remove the bulk liquid phase; (2) reacting for 2 to $4 \mathrm{~h}$ with supercritical $\mathrm{CO}_{2}-\mathrm{SO}_{2}$, at a molar composition of $98 \% / 2 \%$, at a temperature of $120^{\circ}$ to $150^{\circ} \mathrm{C}$, and a pressure of $13.89 \mathrm{MPa}$ (2015 psia); and (3) washing of treated wood chips with water until the filtrate became colorless. Overall carbohydrate yields of $83 \%$ could be achieved using either pretreatment method, despite selective removal of arabinogalactan and glucomannan fractions. Treatment with $50 \%$ (v/v) MEA removed $91 \%$ of the lignin in the wood chips, whereas a 4-h treatment with supercritical $\mathrm{CO}_{2}-\mathrm{SO}_{2}$ at a temperature of $130^{\circ} \mathrm{C}$ removed only $61 \%$. Removal of lignin correlated with improved rates and yields of enzymatic hydrolysis. Delignification occurred without loss of hemicellulose in the MEA process, whereas increased delignification was accompanied by increased loss of xylan in $\mathrm{SCF} \mathrm{CO}_{2}$ treatment.

Chou (1986) examined the potential for supercritical ammonia pretreatment of lignocellulosic materials. Substrates investigated include chipped white birch, southern red oak, aspen, loblolly pine, sitka spruce, Douglas fir, corn stalks, and bagasse. Southern red oak chips had an average dimension of $20 \times 15 \times 4 \mathrm{~mm}$. Treatment consisted of a heat-up period of $15-20 \mathrm{~min}$ followed by incubation from $5 \mathrm{~min}$ to $2 \mathrm{~h}$ at a temperature of $100^{\circ}-200^{\circ} \mathrm{C}$, an ammonia loading of $10-400 \mathrm{~kg} \mathrm{NH} / \mathrm{m}^{3}$ reactor volume, and an operating pressure of 10.34-13.10 MPa (1500-1900 psia); experiments were designed to bracket the critical point for ammonia $\left(132^{\circ} \mathrm{C}\right.$ and $11.28 \mathrm{MPa}$ [1636 psia] with an ammonia density of $234 \mathrm{~kg}$ $\mathrm{NH}_{3} / \mathrm{m}^{3}$ ). Following incubation, the reactor was air-cooled before removing pretreated samples, which were then left overnight in a fume hood to evaporate residual ammonia; no explosive decompression was employed. Samples were neutralized by dropwise addition of $0.1 \mathrm{~N} \mathrm{HCl}$ prior to enzymatic hydrolysis. Treatment yielded very few extractives despite the strong solvent power of SCF ammonia, leading Chou (1986) to hypothesize that extractives solubilized during treatment recondensed and/or precipitated as the reactor cooled. Microscopic examination of treated materials showed swollen fiber bundles and shrunken vacuoles, consistent with an alkali swelling mechanism. No influence on moisture content was observed for water loadings ranging from $10 \%$ to $55 \%$ on a dry biomass basis.

SCF ammonia pretreatment of agricultural residues (bagasse and corn stalks) and hardwoods (aspen and red oak) enabled enzymatic hydrolysis yields on cellulose of greater than $90 \%$ of theoretical to be achieved. Hydrolysis yields on hemicellulose showed greater variability, with a low of $65 \%$ of theoretical for bagasse and a high of $90 \%$ for corn stalks. Maximum hydrolysis yields for softwoods (spruce, pine, and fir) were only $25 \%$ and $5 \%$ of theoretical on cellulose and xylan, respectively. Ammonia treatment was most effective at temperatures and pressures near the critical point, with a temperature optimum of $150^{\circ} \mathrm{C}$ noted; hydrolysis yields fell off at subcritical conditions and at conditions well above the critical point. 
Experiments using southern red oak in both chipped $(20 \times 15 \times 4 \mathrm{~mm})$ and ground (20-40 mesh or 0.42$0.85 \mathrm{~mm}$ ) form were conducted to assess the influence of particle size. Ammonia-treated chips were ground to pass a 20-mesh screen prior to enzymatic hydrolysis to permit an unbiased comparision of hydrolysis yields. Similar hydrolysis yields of $93 \%$ and $75 \%$ of theoretical conversion of cellulose and xylan, respectively, were observed with both particle sizes. These results indicate that effective ammonia pretreatment does not require milling of biomass to small size.

The advantages cited by Chou (1986) for the use of supercritical ammonia pretreatment are (1) wood chips from a commercial chipper can be used directly; (2) the method is effective for both hardwoods and agricultural residues; (3) exhausted ammonia is relatively easy to recover for reuse; (4) near complete retention of lignin, hemicellulose, and cellulose fractions is achieved; and (5) no inhibitors are formed so that pretreated material can be used directly as a substrate for renewable fuels and chemicals production, or to produce animal feeds. No economic analysis quantifying the cost of ammonia pretreatment was provided, however.

The changes in physical and chemical structure that occur following SCF ammonia pretreatment were examined in a related study by Weimer et al. (1986). Air-dried southern red oak (hardwood) and Douglas fir (softwood) chips containing 6\%-8\% water (dry basis) were ground to pass through a 12-mesh (1.7-mm) screen and then incubated with ammonia near or above its critical temperature and pressure following the procedure of Chou (1986). An increase in nitrogen content of pretreated materials was determined to be the result of amidation reactions. Solute exclusion studies indicated that the total pore volume of the samples was increased following pretreatment, but that this increase occurred without a corresponding increase in pore width. Increased porosity (pore volume) occurred without a change in cellulose, hemicellulose, or lignin content. Weimer et al. (1986) hypothesized that SCF ammonia pretreatment caused ammonolysis of ester linkages between hemicellulose and lignin but did not solubilize lignocellulosic components. Reduced hemicellulose-lignin bonding presumably increased swelling and thus total pore volume, whereas retention of hemicellulose and lignin components prevented the maximum pore width from increasing. The maximum pore width was $50 \AA$ and $12-38 \AA$ for ammonia-treated hardwoods and softwood (Douglas fir), respectively. The higher digestibility of hardwoods relative to softwoods was attributed to the inability of the treatment to increase the maximum pore width in softwood to above $-43 \AA$, the minimum pore width estimated to be required for Trichoderma reesei cellulase enzyme penetration.

Li and Kiran (1988) performed a thorough study of the interactions between supercritical fluids and lignocellulosic materials. Continuous SCF extraction of red spruce, sugar maple, and white pine sawdust, sieved to pass through a $1-\mathrm{mm}$ mesh, was examined using a broad variety of potential SCF solvents. Extraction was carried out for $1-2 \mathrm{~h}$ at a temperature of $37^{\circ}-200^{\circ} \mathrm{C}$, and a pressure of $20.68-35.85 \mathrm{MPa}$ (3000-5200 psia); operating conditions varied according to the SCF extractant used. Pure SCFs examined included carbon dioxide, ethylene, nitrous oxide, $n$-butane, ammonia, and methylamine. Binary mixtures evaluated were carbon dioxide-ethanol, carbon dioxide-water, carbon dioxide-sulfur dioxide, nitrous oxidemethylamine, ethylene-ammonia, ammonia-water, and ethanol-water. A ternary mixture of carbon dioxidewater-ethanol was also examined. Extractions in pure carbon dioxide, ethylene, nitrous oxide, and nbutane were not substantial, and $\mathrm{Li}$ and Kiran (1988) concluded that interactions between these solvents and lignocellulosics were nonreactive. In contrast, dissolution of certain components during ammonia and methylamine SCF extraction indicated reactive interactions between these SCFs and lignocellulosics. The efficacy of binary mixtures was strongly composition-dependent, making generalizations difficult. Of all of the SCFs examined, methylamine was most reactive with lignin, whereas ammonia and carbon dioxidewater mixtures were more reactive with carbohydrate. 


\section{Supercritical Fluid Explosion}

The potential of a pretreatment based on incubation in supercritical fluid followed by explosive decompression was evaluated in a Small Business Innovation Research Phase I study (Castor 1991). The effectiveness of supercritical carbon dioxide, ethane, ethylene, Freon-22, nitrous oxide, and propane in binary mixture with water was assessed. Hardwood red oak, softwood white pine, and newsprint were used as representative biomass types. Woody materials were tested as chips (10 $\mathrm{mm} \times 6 \mathrm{~mm} \times 1 \mathrm{~mm})$, cubes ( $6 \mathrm{~mm}$ on each side) and/or shavings $(25 \mathrm{~mm} \times 6 \mathrm{~mm} \times 1 \mathrm{~mm})$, whereas newspaper was tested as strips (6-mm to 10-mm wide). Experiments investigated the effects of the following parameters: pressure (up to $69 \mathrm{MPa}$ [10,000 psia]); temperature (up to $200^{\circ} \mathrm{C}$ ); residence or soak time (1 to $60 \mathrm{~min}$ ); and biomass moisture content.

Pretreated samples were enzymatically hydrolyzed for $3 \mathrm{~h}$ and assayed for total reducing sugars (as glucose). Enzymatic conversion efficiency was defined as the percent weight loss of the solid fraction (total solids, dry weight basis), with weight loss determined from the amount of soluble reducing sugars produced during enzymatic hydrolysis. Enzymatic conversion efficiencies of unwashed pretreated samples were below $25 \%$ for softwood and hardwood chips using SCF $\mathrm{CO}_{2}$ over the range of conditions examined. In comparision, enzymatic conversion efficiencies for untreated hardwood samples were below $4 \%$. The efficacy of $\mathrm{SCF} \mathrm{CO}$ pretreatment of softwood increased but remained below $25 \%$ when 2 mol \% ethanol was added to provide a polar entrainer. Most of the experiments were carried out at high temperatures (approximately $200^{\circ} \mathrm{C}$ ) and long residence times $(1 \mathrm{~h})$, however. Thus, the low yields obtained may be more a result of the conditions examined, which favor degradative reactions, than of ineffective pretreatment per se. Notably, enzymatic conversion efficiencies of approximately $50 \%$ were achieved on newsprint following 1-min exposure to $\mathrm{SCF} \mathrm{CO}_{2}$ at $13.89 \mathrm{MPa}(2015 \mathrm{psia})$ and $57^{\circ} \mathrm{C}$ (in comparision to an enzymatic conversion efficiency of $15 \%$ for untreated newsprint).

The performance of the different SCFs was examined by incubating softwood cubes for $1 \mathrm{~h}$ at $200^{\circ} \mathrm{C}$ and $69 \mathrm{MPa}(10,000 \mathrm{psia})$. The SCFs nitrous oxide, ethane, and Freon-22 all showed somewhat higher efficacy than SCF $\mathrm{CO}_{2}$, although in all cases enzymatic conversion efficiencies on pretreated materials were below $10 \%$. The fact that the experiments were performed under conditions that cause significant substrate degradation makes interpretation of the results difficult. The potential of pretreating lignocellulosics using SCF explosion will not be clear until further experimental results are available.

\section{Discussion}

\section{Development of Improved Pretreatment Processes}

The specific objectives of pretreatment are dictated by the overall objectives of the biomass-to-ethanol process. First, pretreatment must be economical for the biomass-to-ethanol process to be profitable. Second, pretreatment must promote effective conversion of available carbohydrate into fermentable sugars so that high ethanol yield can be achieved. This means that degradation or loss of carbohydrate must be avoided during pretreatment. Because it is also desirable to maximize the rate of enzymatic conversion, pretreatment must yield a highly digestible material that is not inhibitory to cell metabolism or extracellular enzyme function. Therefore, it is preferable to avoid the formation of inhibitory products and/or the need for washing. High sugar losses occur if pretreated material must be washed prior to enzymatic hydrolysis. It is also sought to minimize the potential for nonspecific binding of enzymes to lignin and other fractions of pretreated biomass, since pretreated material is most cost effectively hydrolyzed using low enzyme loadings (the exact level depending on enzyme cost). 
Despite a clear understanding of the objectives of pretreatment, development of effective and economic pretreatments is hindered by uncertainty about the factors influencing enzymatic hydrolysis. As pointed out in the section on factors affecting digestibility, there is considerable controversy about how to conceptualize the hydrolysis process, with accessible surface area and/or crystalline cellulose reactivity hypothesized to be controlling factors. Although the literature shows that hydrolysis rates and susceptibilities to pretreatments vary widely among materials, it has not been established if these differences are due to differences in porosity (accessible surface area) or reactivity. Two fundamental questions that need to be answered are (1) What determines the extent to which surfaces are accessible to enzymes?; and (2) What determines specific reactivity of a lignocellulosic material (reactivity per unit accessible surface area)? Pretreatment processes that are more energetically and chemically efficient can be developed once the effects of structural and compositional characteristics on accessible surface area and specific reactivity are understood.

Besides a general need for fundamental studies, there is a specific need to standardize how experiments are conducted and how results are reported (Dale 1985). Substrate standards for comparing pretreatments are also needed. Utilizing representative feedstock standards for hardwoods, softwoods, herbaceous crops, or grasses (at specified particle size and moisture content) would provide a benchmarkenabling researchers to compare their results with those of others. Without a reference benchmark it remains difficult to compare data, as a perusal of the literature makes clear. A uniform method for reporting enzymatic hydrolysis results also needs to be established; reporting hydrolysis yields in terms of percent of theoretical conversion might be the best approach. Accessible surface area estimation is another area in which a reference benchmark needs to be developed. No comparative study of the different accessible surface area estimation methods is available, so it is impossible to compare results obtained by different methods. Thus, a benchmark study of interfacial area measurement is needed.

The development of improved pretreatments is motivated by the need to overcome disadvantages associated with NREL's dilute acid pretreatment process, which include: suboptimal enzymatic hydrolysis rates and yields; the need for post-treatment neutralization; and the need for expensive materials of construction (that can withstand the corrosive nature of high-temperature dilute acid processing). Opportunities for developing improved pretreatments are limited by incomplete lnowledge about lignocellulose structure and the nature of the interactions between components of lignocellulose and pretreatment chemicals, and the factors controlling enzymatic hydrolysis. Further information about any of these topics will hasten the development of improved or alternative pretreatment processes.

Research to develop improved pretreatment processes is directed at: (1) understanding the extent to which further improvements in the dilute acid hydrolysis pretreatment process can economically be made; and (2) identifying alternative pretreatments that warrant exploration. In the near term, the economic feasibility of modifying the NREL process to enable more rapid enzymatic hydrolysis needs to be evaluated. The extent to which changes in energy and/or chemical inputs can be used to improve bioconversion rates and yields, reduce byproduct formation, and/or reduce energy requirements needs to be determined using sensitivity analyses. One sensitivity analysis can determine the breakeven point at which increases in hydrolysis rate and yield no longer compensate for increases in the cost of pretreatment. Another sensitivity analysis can quantify the importance of byproduct formation by examining the significance of waste disposal costs and/or chemical recovery requirements on the overall economics of a commercialscale biomass-to-ethanol process.

Pretreatment processes that produce high yields without byproduct formation are desired in the longer term. Similar questions to those posed above must be answered to evaluate the potential of proposed alternative pretreatment processes. For instance, does the improvement in enzymatic digestibility gained by pretreatment compensate for the cost of pretreatment? If an existing process is being modified, does the marginal increase in rate or yield achieved pay for the incremental increase in pretreatment cost? As 
mentioned before, sensitivity analyses of overall process economics as functions of yield and enzymatic hydrolysis rate can be used to assess how the permissible cost of pretreatment varies with efficacy. Results of such sensitivity analyses can be used to draw conclusions regarding the best options for developing improved pretreatment processes.

\section{Overview of Reviewed Pretreatments}

\section{Mechanical Comminution}

The cost of pretreatment is sensitive to comminution costs and reducing comminution requirements will greatly improve pretreatment economics. The comminution literature shows that fine grinding of biomass particles to sizes below $150 \mu \mathrm{m}$ significantly improves bioconversion rates and yields. However, fine grinding to such small size is not economically justified because it requires about $25 \%$ of the total energy contained in the material. Further analysis on the effect of input particle size on the efficacy of the various pretreatment methods needs to be performed to better quantify the breakeven point where increased comminution is no longer profitable.

Chou (1986) and Holtzapple (1990b) have shown that both super- and subcritical ammonia pretreatment are effective on coarsely chipped biomass. Thus, for AFEX or SCF $\mathrm{NH}_{3}$ pretreatment there is a point beyond which further comminution is ineffective. Unfortunately, both Chou (1986) and Holtzapple (1990b) had to finely grind coarse ammonia-treated biomass to be able to compare hydrolysis yields with those obtained from materials that were finely ground prior to ammonia treatment. Consequently, it is unclear to what extent post-treatment fine grinding is necessary to achieve high enzymatic hydrolysis yields.

Experiments need to be carried out to determine the optimal particle sizes for pretreatment and enzymatic hydrolysis. It is important to quantify how the initial hydrolysis rate or the amount of adsorbed enzyme per gram of material varies as a function of particle size following post-treatment fine grinding. Since enzyme coverage per gram of material is low for large particles, some post-treatment grinding is probably necessary to achieve high bioconversion rates and yields. (Does this reflect limited external surface area or limited accessibility to internal pores?) If the claims made by Holtzapple (1990b) about the energetic efficiency of wet grinding are correct, the cost of ammonia pretreatment will be reduced using posttreatment wet grinding. Holtzapple's claims can be verified and/or quantified by having several equipment vendors determine power requirements for wet grinding ammonia-treated biomass. Finally, if claims about lower power requirements for wet grinding are supported by the results of vendors' tests, the use of posttreatment grinding should be considered for the dilute acid process. It may be more economical to use coarse chips in dilute acid treatment and then to wet grind pretreated material prior to enzymatic hydrolysis, provided that with coarse chips uniform acid impregnation can be achieved and heat transfer limitations can be avoided.

\section{Low-temperature Alkali Treatment}

Swelling treatment by soaking in alkali at low temperature increases the digestibility of lignocellulosics. Literature on swelling treatments indicates that dilute $\mathrm{NaOH}$ and liquid or gaseous $\mathrm{NH}_{3}$ increase swelling of lignocellulosic by alkali-catalyzed cleavage of uronic esters that crosslink hemicellulose to holocellulose and/or lignin. The presence of crosslinks that are resistant to alkaline hydrolysis is apparently what determines the extent of swelling; the importance of hydrogen bonding on swelling of crystalline cellulose is unclear. A presoak in dilute $\mathrm{NaOH}$ is often used to swell the lignocellulosic structure prior to treatment with some other agent, but not as a stand-alone pretreatment. (Soaking in $\mathrm{NaOH}$ is also used to delignify pretreated material, but delignification methods are not addressed in this report.) In contrast, treatment with ammonia at low-temperature $\left(\mathrm{T}<140^{\circ} \mathrm{C}\right)$ is used as a stand-alone pretreatment: enzymatic 
hydrolysis yields of greater than $90 \%$ of theoretical can be achieved following ammonia (AFEX) treatment of low-lignin-content materials. Dale and Moreira (1982) hypothesize that low-temperature ammonia treatment is effective because of the tenfold lower viscosity and surface tension of liquid ammonia relative to liquid water, which presumably enables excellent penetration of liquid (or gaseous) ammonia into lignocellulosic materials.

It is unlikely that hemicellulose is removed (solubilized) during AFEX treatment, since very little free water is present. Thus, although photomicrographs show that biomass is partially defibrated by AFEX treatment, it is unclear to what extent accessible surface area is increased by exposure to ammonia. (The contribution of explosive decompression to increased surface area is discussed below in the section on explosive decompression-based methods.) Disruption of hemicellulose-lignin crosslinks by ammonolysis reduces structural integrity of the lignocellulosic matrix, but does not necessarily increase porosity (accessible surface area). Porosity may not be increased until the material has been slurried (prior to enzymatic hydrolysis) and the hemicellulose fraction solubilized.

\section{Dilute Acid Hydrolysis}

Overall, high-temperature dilute acid pretreatment is effective, although enzymatic hydrolysis rates and yields on treated materials remain suboptimal. The literature survey shows a few areas in which further progress can be made. In addition to studies to explore the influence of particle size (outlined above), there is a need to develop a comprehensive model that can be used to predict hydrolysis yields, since the kinetic model described in the section on dilute acid hydrolysis has several weaknesses. First, the potential influence of particle size is not considered. A combined model incorporating mass and heat transfer considerations with hydrolysis kinetics could be used to determine optimal pretreatment conditions. Second, the model is based on the unproven and unsupported assumption that xylan is composed of both fast- and slow-hydrolyzing fractions. Although rate measurements suggest that two hemicellulose fractions exist, the theoretical basis for the existence of two xylan fractions.is unclear. As discussed in the section on the composition and structure of biomass, hemicellulose composition varies widely, with different biomass species primarily containing different amounts of glucomannan and xylan. In no species, however, do the respective fractions of these components correspond to the approximately 70:30 ratio used in modeling work to characterize the proportion of fast- and slow-reacting hemicellulose fractions. It could be that other factors such as bond strengths or geometric and/or structural features underlie the differences in hemicellulose hydrolysis rates. Further studies will be necessary to resolve this issue. Finally, the utility of the model is hampered by inconsistencies in the way in which researchers estimate dependence on effective acid concentration.

\section{Explosive Decompression-based Methods}

The literature shows that exposure to high-temperature $\left(\mathrm{T}>160^{\circ} \mathrm{C}\right)$ steam followed by explosive decompression increases lignocellulosic digestibility. The mechanism of steam explosion pretreatment is similar to that in dilute acid pretreatment wherein hemicellulose is rapidly hydrolyzed. In contrast to the dilute acid process, however, the pore structure of steam-exploded biomass probably does not open up as a result of hemicellulose solubilization until the material is washed; before washing, hydrolyzed hemicellulose may not be fully solubilized. Further research is needed to better characterize the lignin fraction that remains following steam explosion pretreatment. Although many studies have shown that hemicellulose degradation products condense with lignin during treatment, forming so-called pseudo-lignin, the properties of this pseudo-lignin fraction need to be more extensively characterized. The results of Brownell et al. (1986) show that the efficacy of steam explosion pretreatment is not affected by the pressure drop used for explosive decompression. Thus, explosive decompression primarily serves to rapidly quench hightemperature hydrolysis reactions. The main disadvantage of steam-explosion-based pretreatment is low 
overall yield because of sugar degradation and removal of solubilized sugars during post-treatment washing.

As in the case of steam explosion, it is doubtful that explosive decompression is important in the ammonia explosion (AFEX) process. Although Dale and Moreira (1982) observed that digestibility increased with increasing pressure drop for explosive decompression, more recent results by Holtzapple et al. (1990a,b) show that the pressure drop for explosive decompression can be reduced without compromising digestibility. Ammonia explosion results therefore support the hypothesis that alkali (ammonia) swelling is the dominant mechanism in the AFEX process rather than explosive decompression. Apparently, operation at higher ammonia partial pressure is advantageous only because it improves penetration of ammonia into lignocellulosic materials.

It is difficult to make a determination on the potential for $\mathrm{CO}_{2}$-based explosive decompression based on the scant results available. The results of Dale and Moreira (1982), who obtained enzymatic hydrolysis yields of $75 \%$ of theoretical on alfalfa pretreated by $\mathrm{CO}_{2}$ explosion at ambient temperature, indicate that this method is effective. Puri and Mamers (1983) carried out $\mathrm{CO}_{2}$ explosion experiments at $200^{\circ} \mathrm{C}$, however, so it is difficult to determine the extent to which their $75 \%$ hydrolysis yields were due to hightemperature hemicellulose autohydrolysis rather than $\mathrm{CO}_{2}$ explosion. Despite uncertainty about efficacy, the concept of a $\mathrm{CO}_{2}$-based pretreatment process is intrinsically attractive, since $\mathrm{CO}_{2}$ produced by fermentation or obtained from boiler flue gas would provide a cheap and readily available source of $\mathrm{CO}_{2}$ feedstock. More definitive studies are needed to assess the potential of $\mathrm{CO}_{2}$-based explosion pretreatment.

\section{Exposure to Supercritical Fluids}

SCF pretreatment of lignocellulosics in the context of ethanol production shows promise when SCF solvents that are reactive with lignin or carbohydrate components are used. Of all of the pure fluids and binary mixtures investigated by $\mathrm{Li}$ and Kiran (1988) for efficacy against lignocellulosic materials, $\mathrm{CO}_{2}$ $\mathrm{H}_{2} \mathrm{O}$ and $\mathrm{NH}_{3}$ were most reactive with carbohydrate components, whereas methylamine was most reactive with lignin. Studies by Chou (1986) and others have shown that SCF pretreatment is most effective when carried out at or near the critical point.

Like $\mathrm{CO}_{2}$ explosion, the potential of SCF CO${ }_{2}$ treatment remains uncertain. Shah et al. (1990) found SCF treatment with a $\mathrm{CO}_{2}-\mathrm{SO}_{2}$ mixture to be effective at temperatures of $120^{\circ}-150^{\circ} \mathrm{C}$, whereas Ritter and Campbell (1986) found treatment with $\mathrm{SCF} \mathrm{CO}_{2}$ to be ineffective at temperatures of $40^{\circ}$ and $100^{\circ} \mathrm{C}$. Dale and Moreira (1982) showed efficacy of $\mathrm{CO}_{2}$ treatment at ambient temperature (subcritical explosive decompression), however, so it is unclear why Ritter and Campbell (1986) found $\mathrm{SCF} \mathrm{CO}_{2}$ pretreatment to be ineffective at relatively low temperatures.

The most promising SCF-based pretreatment results were obtained by Chou (1986) using SCF ammonia. In contrast to the lower pressure AFEX process, pretreatment with SCF ammonia was effective on aspen and red oak hardwood. SCF ammonia pretreatment results further support the hypothesis that it is primarily the extent to which ammonia penetrates into a lignocellulosic material that determines the effectiveness of ammonia pretreatment (since no explosive decompression was employed). Several other aspects of Chou's (1986) study deserve comment. First, although Chou (1986) neutralized air-dried SCF ammonia treated material prior to enzymatic hydrolysis, it is not clear that this is necessary; Dale et al. (1985) successfully hydrolyzed AFEX treated materials that had not been neutralized beforehand. Second, the reported temperature optimum of $150^{\circ} \mathrm{C}$ is likely to be high because xylose and/or xylobiose degradation were not considered; Chou (1986) based the effectiveness of treatment on the combined glucose and cellobiose yields alone, so it is primarily hexose/hexosan conversion that decreases above and below this "temperature optimum." Finally, in contrast to results obtained by Dale and Holtzapple et al., no influence on moisture content was observed for water loadings ranging from $10 \%$ to $55 \%$ on a dry 
biomass basis. Why SCF treatment is less sensitive to the presence of water is unclear. It may be that water penetration markedly increases in SCF treatment relative to AFEX treatment. If this is true, then there is some lower limit for water loading below which the effectiveness of SCF $\mathrm{NH}_{3}$ treatment will fall off. Further experiments are needed to test this hypothesis.

\section{Prospects for the Future}

In the short term, there is a need to improve the dilute acid process because hydrolysis rates remain low. Increased hydrolysis rates can be obtained if more severe conditions or different treatments are employed, but generally increased rate comes at the expense of reduced yield. For example, Torget and Grohmann (1990c) have obtained very rapid hydrolysis rates by delignifying (with $\mathrm{NaOH}$ ) dilute acid pretreated material prior to enzymatic hydrolysis; yield was reduced because of losses associated with $\mathrm{NaOH}$ delignification. Low rates of enzymatic hydrolysis of dilute-acid-pretreated material (not subsequently delignified) imply that lignin that remains following treatment either directly blocks enzymatic attack, competitively binds enzyme(s), or otherwise inhibits enzyme binding at the cellulose surface. It needs to be determined to what extent each of these mechanisms is operative.

The structural organization of individual fiber cells suggests that partial delignification, for example, selective delignification of the outer portion of the compound middle lamellae, might dramatically improve the rate and/or extent of enzymatic hydrolysis of dilute acid pretreated hardwood. The ability to achieve selective delignification depends on the path by which pretreatment chemicals and enzymes penetrate into the wood matrix; i.e., do penetrating chemicals or enzymes enter a lignocellulosic matrix from the fiber cell wall lumen side and diffuse into the matrix, or do they enter through openings (pits) in the fiber cell wall and diffuse from the outside inward? The channel system within lignocellulose is undoubtedly an important structural feature (Schurz 1986), although the precise pathway by which chemical reagents or enzymes penetrate into a lignocellulosic matrix is unclear. Radially uniform penetration of delignifying agents into fiber cells may not be possible, however, since heat and mass transfer studies by Brownell et al. (1986), Tillman et al. (1990), and others have documented that lignocellulosic structural asymmetry favors transport in the axial rather than radial direction. Tillman et al. (1990), for example, determined that acid diffusivities are two- to threefold higher in the direction of the fiber axis than in the radial or tangential directions. Further study is required to determine if selective delignification of the outer (or inner) portion of the compound middle lamellae is feasible.

From a mechanistic standpoint, there are notable similarities among many of the pretreatment methods. With the exception of comminution, for example, pretreatment methods usually employ catalysts (dilute acid, sulfur dioxide, alkali, etc.) because this enables the processes to be carried out at lower temperatures than otherwise, which increases yield. Another commonality is that most pretreatments are performed at sufficiently high temperature to maximize hemicellulose hydrolysis rates and thereby minimize treatment time. The significance of mass and heat transport resistances within lignocellulosic materials is evidenced by the severe conditions ( $\mathrm{T}>140^{\circ} \mathrm{C}$ in the presence of a catalyst) generally required for effective pretreatment. Dilute acid hydrolysis and steam explosion pretreatments, for example, are effective only at temperatures above $140^{\circ} \mathrm{C}$. $\mathrm{CO}_{2}$-based explosive decompression and many SCF treatments may therefore also require high-temperature operation for efficacy.

In the longer term, lower temperature pretreatment processes that avoid the problem of rapid sugar degradation at high temperatures are desired. At present, comminution and ammonia pretreatment are the only processes with proven efficacy at temperatures below $140^{\circ} \mathrm{C}$; further studies are required to assess the potential of $\mathrm{CO}_{2}$-based pretreatments at low temperatures. The ability to achieve effective pretreatment at lower temperatures using ammonia is apparently a consequence of the low surface tension and viscosity of ammonia relative to water, as hypothesized by Dale and Moreira (1982). Besides efficacy at low temperatures, ammonia-based pretreatments are advantageous because large chips can be used, there is no 
byproduct formation, ammonia is relatively easy to recover for reuse, and residual ammonia in the product has value as a nitrogen source. This last advantage appears to be substantial, since discussions with M. Holtzapple (1990c) indicate that current development of the AFEX process is aimed at producing highvalue feeds and feed supplements from agricultural residues. Ammonia-based pretreatment requires moderate- to high-pressure operation 1.03-1.38 MPa (150-200 psia) for subcritical AFEX or 10.34-13.79 $\mathrm{MPa}$ (1500-2000 psia) for SCF $\mathrm{NH}_{3}$ treatment) and a feasibility study needs to be performed to examine the economics of ammonia treatment as a function of compression requirements.

Supercritical treatments are undoubtedly less economical than low-pressure treatments because of higher compression requirements. An analysis carried out by Vick Roy and Converse (1985), for example, indicates that economic operation of a SCF pretreatment process using $\mathrm{H}_{2} \mathrm{O}-\mathrm{SO}_{2}$ would require achieving $95 \%$ sugar yields, and greater than $98 \%$ recovery of $\mathrm{SO}_{2}$. Since yields this high have not yet been realized, it is clear that there are significant challenges to be overcome to develop cost-effective SCF-based pretreatments. In the longer term, however, SCF treatments offer the potential to achieve greater selectivities and/or efficacies, and should be pursued.

\section{Conclusions}

Major factors affecting the rate and degree of enzymatic hydrolysis of lignocellulosic biomass are surface area, cellulose crystallinity, and the nature of the lignin/hemicellulose matrix or sheath surrounding cellulose microfibrils. Pretreaments to improve enzymatic conversion are usually composed of a combination of mechanical, physical, and chemical steps. Mechanical pretreatment typically consists of biomass comminution. Physical pretreatments include high-temperature incubation, explosive decompression, and others. Chemical treatments include acid- or base-catalyzed prehydrolysis of hemicellulose, exposure to swelling reagents to decrystallize and/or solubilize cellulose, and/or solubilization of lignin by various chemical reagents. Although single treatments such as comminution, swelling, or chemical reaction can dramically improve enzymatic hydrolysis rates and yields, single-step processes are prohibitively costly when carried out to the extent required to attain high yields. Fine grinding of biomass particles to sizes below $150 \mu \mathrm{m}$, for example, can significantly improve bioconversion rates, but cannot be justified because it requires roughly $25 \%$ of the total energy contained in the material. On the other hand, economic treatment with concentrated chemical reagents is difficult because the chemicals must be cost effectively recovered and reused.

Overall yield is the most important factor in a commercial-scale biomass-to-ethanol process, and research on improved pretreatment processes must therefore focus on minimizing, or preferably eliminating altogether, degradation of the carbohydrate fraction of lignocellulosic biomass. Steam-explosion-based processes, although already commercially developed, are unattractive in the long term because the formation of degradation products reduces yields. High-temperature, dilute acid processes, despite nearterm potential, also are unfavorable in the long term, because of high-temperature-catalyzed sugar degradation and because neutralization of acidic pretreatment hydrolyzate generates substantial quantities of inert byproducts (e.g., gypsum), which represent a waste disposal burden. Chemical recovery requirements make more chemical intensive processes, such as concentrated acid hydrolysis, organosolv, and many pulping techniques, unattractive.

In the near term, the potential to achieve further improvements in the existing (NREL) dilute acid hydrolysis process needs to be explored. The economic feasibility of modifying this process to enable more rapid enzymatic hydrolysis of pretreated biomass needs to be evaluated. Sensitivity analyses can be performed to understand the extent to which additional energy and/or chemical inputs can be used to improve bioconversion rates and yields or to reduce energy requirements. One sensitivity analysis can determine the breakeven point at which increases in hydrolysis rate and yield no longer compensate for 
increases in the cost of pretreatment. Another sensitivity analysis can examine the importance of potential waste disposal costs and/or chemical recovery requirements on the overall economics of a commercialscale biomass-to-ethanol process. This analysis is needed to quantify the advantages of avoiding byproduct formation.

In the longer term, research on processes that offer the potential of producing high yields with little or no byproduct formation should be pursued. Lower temperature processes are particularly attractive because they eliminate the problem of yield losses caused by high-temperature sugar degradation. Among the lower temperature pretreatments proposed in the literature, AFEX shows promise, although primarily for herbaceous crops and agricultural residues. Supercritical fluid-based pretreatments are less developed, but also warrant further study; in contrast to AFEX, supercritical ammonia treatment is effective on hardwoods. Although developed to the least extent, alternative explosive decompression processes using gases other than ammonia (e.g., carbon dioxide) may also hold promise. It is recommended that these emerging technologies be further explored and developed.

\section{References}

Beer, R.; Peter, S. (1985). "High Pressure Extraction of Lignin from Wood." Supercritical Fluid Technology. Penninger, J. M. L.; Radosz, M.; McHugh, M. A.; Krukonis, V.J., editors. The Netherlands: Elsevier Science Publishers, pp. 385-396.

Brennan, A. H.; Hoagland, W.; Schell, D. J. (1986). "High-Temperature Acid Hydrolysis of Biomass using an Engineering-scale Plug Flow Reactor: Results of Low Solids Testing." Biotech. Bioeng. Symp. (17); pp 53-70.

Brownell, H. H.; Saddler, J. N. (1984). "Steam-explosion Pretreatment for Enzymatic Hydrolysis." Biotech. Bioeng. Symp. (14); pp. 55-68.

Brownell, H. H.; Yu, E. K. C.; Saddler, J. N. (1986). "Steam-explosion Pretreatment of Wood: Effect of Chip Size, Acid, Moisture Content and Pressure Drop." Biotech. Bioeng. (28); pp. 792-801.

Burns, D. S.; Ooshima, H.; Converse, A. O. (1989). "Surface Area of Pretreated Lignocellulosics as a Function of the Extent of Enzymatic Hydrolysis." Appl. Biochem. Biotech. (20/21); pp. 79-94.

Cahela, D. R.; Lee, Y. Y.; Chambers, R. P. (1983). "Modeling of Percolation Process in Hemicellulose Hydrolysis." Biotech. Bioeng. (25); pp. 3-17.

Castor, T. P. (1991). SBIR Phase 1 Final Report on Critical Fluid Comminution of Biomass (DOA Agreement No. 90-33610-5111). Arlinton, MA: Bio-Eng, Inc.

Chang, M. M.; Chou, Y. C. T.; Tsao, G. T. (1981). "Structure, Pretreatment and Hydrolysis of Cellulose." Adv. Biochem. Eng. (20); pp. 15-42.

Chou, Y. C. T. (1986). "Supercritical Ammonia Pretreatment of Lignocellulosic Materials." Biotech. Bioeng. Symp. (17); pp. 18-32.

Chum, H. L.; Douglas, L. J.; Feinberg, D. A.; Schroeder, H. A. (1985). Evaluation of Pretreatments of Biomass for Enzymatic Hydrolysis of Cellulose. SERITP-231-2183. Golden, CO: Solar Energy Research Institute. 
Clark, T. A.; Mackie, K. L. (1987). "Steam Explosion of the Softwood Pinus radiata with Sulfur Dioxide Addition. I. Process Optimization." J. Wood Chem. Tech. (7:3); pp. 373-403.

Converse, A. O.; Ooshima, H.; Burns, D. S. (1990). "Kinetics of Enzymatic Hydrolysis of Lignocellulosic Materials based on Surface Area of Cellulose Accessible to Enzyme and Enzyme Adsorption on Lignin and Cellulose." Appl. Biochem. Biotech. (24/25); pp. 67-73.

Converse, A. O.; Kwarteng, I. K.; Grethlein, H. E.; Ooshima, H. (1989). "Kinetics of Thermochemical Pretreatment of Lignocellulosic Materials." Appl. Biochem. Biotech. (20/21); pp. 63-78.

Dale, B. E.; Moreira, M. J. (1982). "A Freeze-explosion Technique for Increasing Cellulose Hydrolysis." Biotech. Bioeng. Symp. (12); pp. 31-43.

Dale, B.; Holtzapple, M. (1989). Technical Summary of Ammonia Freeze Explosion. Unpublished.

Dale, B. E. (1985). "Cellulose Pretreatments: Technology and Techniques." Annual Reports on Fermentation Processes (8); pp. 299-323.

Dale, B. E.; Henk, L. L.; Shiang, M. (1985). "Fermentation of Lignocellulosic Materials Treated by Ammonia Freeze Explosion." Dev. Ind. Microbiol. (26); pp. 223-233.

Datta, R. (1981). "Energy Requirements for Lignocellulose Pretreatment Processes." Proc. Biochem. 16 (June/July); pp. 16-19, 42.

Fan, L.T.; Lee, Y-H.; Beardmore, D. H. (1980). "Mechanisms of the Enzymatic Hydrolysis of Cellulose: Effects of Major Structural Features of Cellulose on Enzymatic Hydrolysis." Biotech. Bioeng. (22); pp. 177-199.

Fan, L. T.; Lee, Y-H.; Gharpuray, M. M. (1982). "The Nature of Lignocellulosics and their Pretreatment for Enzymatic Hydrolysis." Adv. Biochem. Eng. (23); pp. 157-187.

Galbe, M.; Zacchi, G. (1986). "Pretreatment of Sallow prior to Enzymatic Hydrolysis." Biotech. Bioeng. Symp. (17); pp. 97-105.

Grethlein, H. E. (1978). "Chemical Breakdown of Cellulosic Materials." J. Appl. Chem. Biotechnol. (28); pp. 296-308.

Grethlein, H. E.; Allen, D. C.; Converse, A. O. (1984). "A Comparative Study of the Enzymatic Hydrolysis of Acid-pretreated White Pine and Mixed Hardwood." Biotech. Bioeng. (26); pp. 14981505.

Grethlein, H. E. (1985). "The Effect of Pore Size Distribution on the Rate of Enzymatic Hydrolysis of Cellulose Substrates." Bio/Technology (3:2), pp. 155-160.

Grohmann, K. (1990). Solar Energy Research Institute, personal communication.

Grohmann, K.; Torget, R.; Himmel, M. (1986). "Dilute Acid Pretreatment of Biomass at High Solids Concentrations." Biotech. Bioeng. Symp. (17); pp. 135-151.

Grohmann, K.; Torget, R.; Himmel, M. (1985). "Optimization of Dilute Acid Pretreatment of Biomass." Biotech. Bioeng. Symp. (15); pp. 59-80. 
Himmel, M.; Tucker, M.; Baker, J.; Rivard, C.; Oh, K; Grohmann, K. (1985). "Comminution of Biomass: Hammer and Knife Mills." Biotech. Bioeng. Symp. (15); pp. 39-58.

Hinman, N. D.; Wright, J. D.; Hoagland, W.; Wyman, C. E. (1989). "Xylose Fermentation: an Economic Analysis." Appl. Biochem. Biotech. (20/21); pp. 391-401.

Hinman, N. D.; Schell, D. J.; Tyson, K. S.; Goodman, B. (1990). Resource Assessment and Economic Analysis of Important Western Region Lignocellulosic Feedstocks for the Production of Fuel Ethanol. Volumes 1 and 2. Solar Energy Research Institute draft report for Western Area Power Administration project BF983232. Golden, CO: Solar Energy Research Institute.

Holtzapple, M. T.; Jun, J-H.; Ashok, G.; Patibandla, S. L.; Dale, B. E (1990a). "The Ammonia Freeze Explosion (AFEX) Process: a Practical Lignocellulosic Pretreatment." Appl. Biochem. Biotech. (28/29); pp. 59-74.

Holtzapple, M. T.; Jun, J-H.; Patibandla, S.; Dale, B. E. (1990b). "Ammonia Fiber Explosion (AFEX) Pretreatment of Lignocellulosic Wastes." Paper presented at the American Institute of Chemical Engineers National Meeting, Chicago, Ilinois, November.

Holtzapple, M. T. (1990c). Texas A\&M University, personal communication.

Horwath, J. A.; Mutharasan, R.; Grossmann, E. D. (1983). "Pentosan Hydrolysis in a Concentrated Slurry System." Biotech. Bioeng. (25); pp. 19-32.

Hradil, G.; Calo, J. M.; Wunderlich, Jr., T. K. (1988). Bimonthly report \#3 for Brown University subcontract No. XK-7-07031-8, submitted to the Solar Energy Research Institute.

Kim, S. B.; Lee, Y. Y. (1987). "Kinetics in Acid-catalyzed Hydrolysis of Hardwood Hemicellulose." Biotech. Bioeng. Symp. (17); pp. 71-84.

Kiran, E. (1987). "Supercritical Fluids and their Interaction with Lignocellulosic Materials and Polymers." Journal of Research at the University of Maine. (III:2); pp. 24-32.

Knappert, D.; Grethlein, H.; Converse, A. (1981). "Partial Acid Hydrolysis of Poplar Wood as a Pretreatment for Enzymatic Hydrolysis." Biotech. Bioeng. Symp. (11); pp. 67-77.

Knappert, D.; Grethlein, H.; Converse, A. (1980). "Partial Acid Hydrolysis of Cellulosic Materials as a Pretreatment for Enzymatic Hydrolysis." Biotech. Bioeng. (22); pp. 1449-1463.

Kwarteng, I. K. (1983). Kinetics of Acid Hydrolysis of Hardwood in a Continuous Plug Flow Reactor. Ph.D. thesis. Dartmouth College, Thayer School of Engineering.

Li, L.; Kiran, E. (1988). "Interaction of Supercritical Fluids with Lignocellulosic Materials." I\&EC Research (27); pp. 1301-1312.

Li, L.; Kiran, E. (1989). "Delignification of Red Spruce by Supercritical Methylamine and Methylaminenitrous Oxide Mixtures." Tappi J. (April); pp. 183-190.

Lin, K. W.; Ladisch, M. R.; Schaefer, D. M.; Noller, C. H.; Lechtenberg, V.; Tsao, G. T. (1981). "Review on Effect of Pretreatment on Digestibility of Cellulosic Materials." AIChE Symp. Ser. No. 207. (77); pp. 102-106. 
Lynd, L. (1990). Dartmouth College, Thayer School of Engineering, personal communication.

Mackie, K. L.; Brownell, H. H.; West, K. L.; Saddler, J. N. (1985). "Effect of Sulfur Dioxide and Sulfuric Acid on Steam Explosion of Aspenwood." J. Wood Chem. Tech. (5:3); pp. 405-425.

Maloney, M. T.; Chapman, T. W.; Baker, A. J. (1985). "Dilute Acid Hydrolysis of Paper Birch: Kinetics Studies of Xylan and Acetyl-group Hydrolysis." Biotech. Bioeng. (27); pp. 355-361.

McDonald, E. C.; Howard, J.; Bennett, B. (1983). "Chemicals from Forest Products by Supercritical Fluid Extraction." Fluid Phase Equilibria. (10); pp. 337-344.

Miller, G. L. (1959). "Use of Dinitrosalicylic Acid Reagent for Determination of Reducing Sugar." Anal. Chem. (41); pp. 426-428.

Millett, M. A.; Baker, A. J.; Satter, L. D. (1976). "Physical and Chemical Pretreatments for Enhancing Cellulose Saccharification." Biotech. Bioeng. Symp. (6); pp. 125-153.

Nystrom, J. (1975). Discussion of "pretreatments to enhance enzymatic and microbiological attack of cellulose materials." Biotech. Bioeng. Symp. (5); pp. 221-224.

Ooshima, H.; Burns, D. S.; Converse, A. O. (1990). "Adsorption of Cellulase from Trichoderma reesei on Cellulose and Lignacious (sic) Residue in Wood Pretreated by Dilute Sulfuric Acid with Explosive Decompression." Biotech. Bioeng. (36); pp. 446-452.

Perry, R. H.; Green, D. W.; Maloney, J. O. (1984). Perry's Chemical Engineers' Handbook, sixth edition. New York: McGraw-Hill.

Poots, V. J. P.; McKay, G. (1979). "The Specific Surfaces of Peat and Wood." J. Appl. Poly. Sci. (23); pp. 1117-1129.

Puri, V. P.; Mamers, H. (1983). "Explosive Pretreatment of Lignocellulosic Residues with High-pressure Carbon Dioxide for the Production of Fermentation Substrates." Biotech. Bioeng. (25); pp. 3149-3161.

Reyes, T.; Bandyopadhyay, S. S.; McCoy, B. J. (1989). "Extraction of Lignin from Wood with Supercritical Alcohols." J. Supercritical Fluids (2); pp. 80-84.

Ripley, E. P. (1990). Enzymatic Hydrolysis, Fermentation, and Protein Recovery of AFEX-treated Coastal Bermuda Grass. M.S. Thesis. Texas A\&M University: Department of Chemical Engineering.

Ritter, D. C.; Campbell, A. G. (1986). "The Effects of Supercritical Carbon Dioxide Extraction on Pine Wood Structure." Biotech. Bioeng. Symp. (17); pp. 179-182.

Root, D. F. (1956). Kinetics of the Acid Catalyzed Conversion of Xylose to Furfural. Ph.D. thesis. University of Wisconsin: Department of Chemical Engineering.

Saeman, J. F. (1945). "Kinetics of Wood Saccharification: Hydrolysis of Cellulose and Decomposition of Sugars in Dilute Acid at High Temperature." Ind. Eng. Chem. (37:1); pp. 43-52. 
Schell, D. J.; Torget, R.; Power, A.; Walter, P. J.; Grohmann, K.; Hinman, N. D. (1991). "A Technical and Economic Analysis of Acid-catalyzed Steam Explosion and Dilute Sulfuric Acid Pretreatments using Wheat Straw or Aspen Wood Chips." Appl. Biochem. Biotech. (28/29); in press.

Schell, D. J.; Riley, C.; Walter, P.; Bergeron, P. (1990). Technical and Economic Analysis of an Enzymatic Hydrolysis Based Ethanol Plant. Golden, CO: National Renewable Energy Laboratory proprietary draft report.

Schultz, T. P.; Biermann, C. J.; McGinnis, G. D. (1983). "Steam Explosion of Mixed Hardwood Chips as a Biomass Pretreatment." Ind. Eng. Chem. Prod. Res. Dev. (22); pp. 344-348.

Schurz, J. (1986). "Studies on the Enzymatic Hydrolysis of Phytomass by Cellulase from Trichoderma reesei." Holzforschung. (40:4); pp. 225-232.

Shah, M. M.; Lee, Y. Y.; Torget, R. (1990). "Pretreatment of Aspen Wood Aimed at High Hemicellulose Retention." Draft proceedings of the Ethanol from Biomass Annual Review Meeting, September 12-13, Lincoln, Nebraska.

Sherrard, E. C.; Kressman, F. W. (1945). "Sugars from Wood: Review of Processes in the United States Prior to World War II." Ind. Eng. Chem. (37:1); pp. 5-8.

Spindler, D. D.; Wyman, C. E.; Grohmann, K.; Torget, R.W. (1989). "Evaluation of Pretreated Woody Crops for the Simultaneous Saccharification and Fermentation Process." FY 1988 Ethanol from Biomass Annual Report, SERI/SP-231-3520. Golden, CO: Solar Energy Research Institute.

Stone, J. E.; Scallan, A. M.; Donefer, E.; Ahlgren, E. (1969). "Digestibility as a Simple Function of a Molecule of Similar Size to a Cellulase Enzyme." Adv. Chem. Ser. (95); pp. 219-241.

Tarkow, H.; Feist, W. C. (1969). "A Mechanism for Improving the Digestibility of Lignocellulosic Materials with Dilute Alkali and Liquid Ammonia." Adv. Chem. Ser. (95); pp. 197-218.

Tillman, L. M.; Lee, Y. Y.; Torget, R. (1990). "Effect of Transient Acid Diffusion on Pretreatment/Hydrolysis of Hardwood Hemicellulose." Appl. Biochem. Biotech. (24/25); pp. 103-113.

Torget, R.; Walter, P.; Himmel, M.; Grohmann, K. (1990a). "Dilute Acid Pretreatment of Corn Cobs, Com Stover, and Short Rotation Crops." Draft proceedings of the Ethanol from Biomass Annual Review Meeting, September 12-13, Lincoln, Nebraska.

Torget, R.; Werdene, P.; Himmel, M.; Grohmann, K. (1990b). "Dilute Acid Pretreatment of Short Rotation Woody and Herbaceous Crops." Appl. Biochem. Biotech. (24/25); pp. 115-126.

Torget, R.; Grohmann, K. (1990c). Solar Energy Research Institute; personal communication.

Torget, R.; Himmel, M.; Wright, J. D.; Grohmann, K. (1988). "Initial Design of a Dilute Sulfuric Acid Pretreatment Process for Aspen Wood Chips." Appl. Biochem. Biotech. (17); pp. 89-104.

Vick Roy, J. R.; Converse, A. O. (1985). "Biomass Hydrolysis with Sulfur Dioxide and Water in the Region of the Critical Point." Supercritical Fluid Technology, Penninger, J. M. L.; Radosz, M.; McHugh, M. A.; Krukonis, V. J., editors. The Netherlands: Elsevier Science Publishers. 
Wang, P. Y.; Bolker, H. I.; and Purves, C. B. (1967). "Uronic Acid Ester Groups in Some Softwoods and Hardwoods." Tappi J. (50:3); pp. 123-124.

Weimer, P. J.; Chou, Y-C. T.; Weston, W. M.; Chase, D. B. (1986). "Effect of Supercritical Ammonia on the Physical and Chemical Structure of Ground Wood." Biotech. Bioeng. Symp. (17); pp. 5-18.

Wenzl, H. F. J. (1970). The Chemical Technology of Wood. New York: Academic Press.

Wong, K. K. Y; Deverell, K. F.; Mackie, K. L.; Clark, T. A. (1988). "The Relationship between Fiber Porosity and Cellulose Digestibility in Steam-exploded Pinus radiata." Biotech. Bioeng. (31); pp. 447-456.

Wright, J. D. (1988). Economics of Enzymatic Hydrolysis Processes. SERI/TP-231-3310. Golden, CO: Solar Energy Research Institute. 


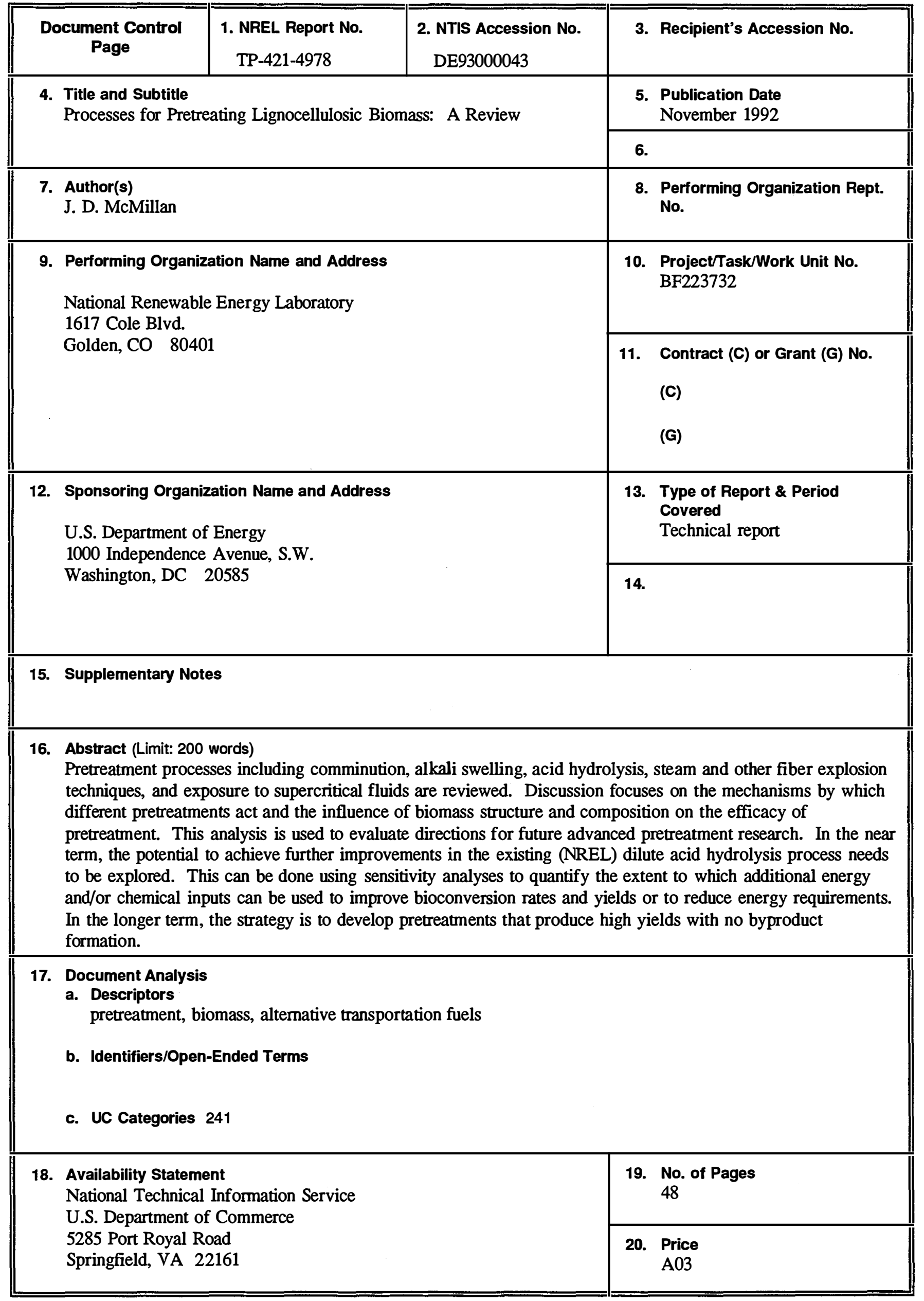

